FEDERAL RESERVE BANK OF SAN FRANCISCO

WORKING PAPER SERIES

\title{
Inflation Expectations and Risk Premiums in an Arbitrage-Free Model of Nominal and Real Bond Yields
}

\author{
Jens H. E. Christensen \\ Federal Reserve Bank of San Francisco \\ Jose A. Lopez \\ Federal Reserve Bank of San Francisco \\ Glenn D. Rudebusch \\ Federal Reserve Bank of San Francisco \\ January 2010 \\ Working Paper 2008-34
}

http://www.frbsf.org/publications/economics/papers/2008/wp08-34bk.pdf

The views in this paper are solely the responsibility of the authors and should not be interpreted as reflecting the views of the Federal Reserve Bank of San Francisco or the Board of Governors of the Federal Reserve System. 


\title{
Inflation Expectations and Risk Premiums in an Arbitrage-Free Model of Nominal and Real Bond Yields ${ }^{\dagger}$
}

\author{
Jens H. E. Christensen \\ Jose A. Lopez \\ Glenn D. Rudebusch \\ Federal Reserve Bank of San Francisco \\ 101 Market Street \\ San Francisco, CA 94105
}

\begin{abstract}
Differences between yields on comparable-maturity U.S. Treasury nominal and real debt, the so-called breakeven inflation (BEI) rates, are widely used indicators of inflation expectations. However, better measures of inflation expectations could be obtained by subtracting inflation risk premiums from the BEI rates. We provide such decompositions using an estimated affine arbitrage-free model of the term structure that captures the pricing of both nominal and real Treasury securities. Our empirical results suggest that long-term inflation expectations have been well anchored over the past few years, and inflation risk premiums, although volatile, have been close to zero on average.
\end{abstract}

\footnotetext{
${ }^{\dagger}$ We thank participants at the FRB/JMCB conference for helpful comments, especially our discussant Stanley Zin, as well as the editors and referees. The views in this paper are solely the responsibility of the authors and should not be interpreted as reflecting the views of the Federal Reserve Bank of San Francisco or the Board of Governors of the Federal Reserve System.

Draft date: January 29, 2010.
} 
From the perspective of monetary policy, just as important as the behavior of actual inflation is what households and businesses expect to happen to inflation in the future, particularly over the longer term. If people expect an increase in inflation to be temporary and do not build it into their longer-term plans for setting wages and prices, then the inflation created by a shock to oil prices will tend to fade relatively quickly. Some indicators of longer-term inflation expectations have risen in recent months, which is a significant concern for the Federal Reserve.

Federal Reserve Chairman Ben S. Bernanke (2008)

\section{Introduction}

In fulfilling their mandate for price stability, central banks around the world are keenly interested in the expectations of future inflation held by households and businesses. Such expectations are widely viewed as key determinants of future inflation, and long-run inflation expectations are considered a useful gauge of central bank credibility. There are two main sources for data on inflation expectations: surveys and financial markets. Policymakers consider the former source to be of somewhat limited use because surveys are typically conducted at a quarterly or, at best, a monthly frequency, so their information on expectations can be stale by the time of a policy meeting. Their infrequency also precludes using surveys to measure the immediate response of inflation expectations to discrete events, such as monetary policy actions or statements. In addition, surveys typically focus on the expectations of inflation over the next year or so, but given policy lags, central banks are interested in longerterm information as well, especially to help assess the credibility of their long-run inflation objectives.

In contrast to surveys, prices in financial markets can provide daily - even intradayreadings on inflation expectations at a wide range of horizons. The markets for nominal bonds, which have a fixed notional principal, and real bonds, which are directly indexed to overall price inflation, are the ones most closely followed for this purpose. ${ }^{1}$ In particular, the principal and coupon payments of U.S. Treasury inflation-protected securities (TIPS) vary with changes in the consumer price index (CPI). Differences between comparable-maturity nominal and real yields are known as breakeven inflation (BEI) rates. Like other central banks, the Federal Reserve closely monitors such BEI rates as high-frequency indicators of inflation expectations. However, as is widely appreciated, BEI rates are imperfect measures of

\footnotetext{
${ }^{1}$ Inflation swaps, another financial instrument that may be useful for gauging inflation expectations, are described in Section 6.
} 
inflation expectations because they also include compensation for inflation risk. That is, a BEI rate could rise if future inflation uncertainty rose or if investors required greater compensation for that uncertainty, even if expectations for the future level of inflation remained unchanged. Obtaining a timely decomposition of BEI rates into inflation expectations and inflation risk premiums is important to central bankers, because they may wish to respond to a change in each component quite differently.

The decomposition of a BEI rate into inflation expectations and an inflation risk premium depends on the correlations between inflation and the unobserved stochastic discount factors of investors. This decomposition requires a model, and in this paper, we use an affine arbitragefree $(\mathrm{AF})$ model, which is the most widely used representation of the term structure in the finance literature. These models specify the risk-neutral evolution of the underlying yieldcurve factors as well as the dynamics of risk premiums under the key theoretical restriction that there are no residual opportunities for riskless arbitrage across maturities and over time. Following Duffie and Kan (1996), affine AF models have been particularly popular because yields are convenient linear functions of underlying latent factors (i.e., state variables that are unobserved by the econometrician) with factor loadings that can be calculated from a system of ordinary differential equations.

Unfortunately, affine AF models can exhibit very poor empirical time-series performance, especially when forecasting future yields (Duffee, 2002). In addition, there are many technical difficulties involved with the estimation of these models, which tend to be overparameterized and have numerous likelihood maxima that have essentially identical fit to the data but very different implications for economic behavior (Kim and Orphanides, 2005, and Duffee, 2008). Researchers have employed a variety of techniques to facilitate estimation including the imposition of additional model structure. ${ }^{2}$ Notably, Christensen, Diebold, and Rudebusch (2007), henceforth CDR, impose general level, slope, and curvature factor loadings that are derived from the popular yield curve structure developed by Nelson and Siegel (1987). In this paper, we show that the resulting affine arbitrage-free Nelson-Siegel (AFNS) model can be readily estimated for a joint representation of nominal and real yield curves. Our estimated joint AFNS model describes the dynamics of the nominal and real stochastic discount factors and allows us to decompose BEI rates of any maturity into inflation expectations and inflation risk premiums.

A sizable research literature has analyzed the inflation risk premium. For example, Ang, Bekaert, and Wei (2008) use a regime-switching AF model estimated on data for nominal

\footnotetext{
${ }^{2}$ Many researchers (e.g., Dai and Singleton, 2002) simply restrict parameters with small $t$-statistics in the first round of estimation to zero.
} 
yields and inflation, and Chernov and Mueller (2008) construct an affine AF model based on nominal Treasury yields and survey inflation forecasts. Grishchenko and Huang (2008) examine inflation risk premium using nominal yields, survey results, and historical inflation data. Chun (2008) also incorporates survey results for inflation and other macroeconomic variables into an AF model of the nominal term strucuture. However, only a few papers have used U.S. data on real yields to estimate an AF model and decompose the BEI rate. Chen, Liu, and Cheng (2005) estimate a two-factor AF representation of nominal and real yields. Hördahl and Tristani (2008) decompose BEI rates using an AF macro-finance model with monthly data on nominal and real yields, inflation, and the output gap. D'Amico, Kim, and Wei (2008), henceforth DKW, estimate an affine AF model of nominal and real yields augmented with data on inflation and survey data on forecasts of short-term nominal interest rates. Adrian and $\mathrm{Wu}(2009)$ propose an affine model of nominal and real yields that also encompasses the dynamics of these series' covariance matrix to characterize BEI rates. We compare our results to this earlier work. ${ }^{3}$

The paper is structured as follows. In Sections 2 and 3, we estimate separate affine AF models for yields on nominal and real Treasury bonds, respectively. The resulting three-factor nominal model and two-factor real model are of some interest on their own and provide useful performance benchmarks for our joint model of nominal and real yields in Section 4. The separate models also provide an important input into the construction of that joint model. Indeed, based on the correlations among the factors of the separate models, we are able to identify a redundant factor, so we find a joint four-factor AF model fits both the nominal and real yield curves quite well. Section 5 then analyzes that estimated model's decomposition of BEI rates into inflation expectations and inflation risk premiums over the period from January 2003 through March 2008. Given the major bond market dislocations observed in late 2008, we use the model for real-time policy analysis of the nominal and real Treasury markets over the period from September 2008 through December 2009 in Section 6. Section 7 concludes.

\section{An empirical AFNS model for nominal yields}

In this section, we estimate an affine AF model on weekly data for nominal zero-coupon U.S. Treasury bond yields. An important preliminary step is to characterize the number and

\footnotetext{
${ }^{3}$ Related studies also have been conducted for nominal and real government bond yields in the U.K. and the euro area; see Joyce, Lildholdt and Sorenson (2009) and Hördahl and Tristani (2007, 2008), respectively. In addition, Haubrich, Pennacchi and Ritchken (2008) as well as Adrian and Wu (2009) estimate affine models of U.S. nominal and real yields with multivariate GARCH processes.
} 


\begin{tabular}{|c|c|c|c|}
\hline $\begin{array}{c}\text { Maturity } \\
\text { (in months) }\end{array}$ & $\begin{array}{c}\text { First } \\
\text { P.C. }\end{array}$ & $\begin{array}{c}\text { Second } \\
\text { P.C. }\end{array}$ & $\begin{array}{c}\text { Third } \\
\text { P.C. }\end{array}$ \\
\hline 3 & -0.4174 & -0.4227 & 0.5248 \\
6 & -0.4294 & -0.3530 & 0.1630 \\
12 & -0.4279 & -0.1952 & -0.2527 \\
24 & -0.3937 & 0.0549 & -0.4660 \\
36 & -0.3546 & 0.2101 & -0.3721 \\
60 & -0.2888 & 0.3745 & -0.0378 \\
84 & -0.2402 & 0.4541 & 0.2284 \\
120 & -0.1908 & 0.5148 & 0.4744 \\
\hline Explain & 0.9417 & 0.0550 & 0.0030 \\
\hline
\end{tabular}

Table 1: First Three Principal Components in Nominal Yields.

The loadings of yields of various maturities on the first three principal components are shown. The final row shows the proportion of all bond yield variability accounted for by each principal component. The data consist of weekly nominal zero-coupon U.S. Treasury bond yields from January 6, 1995, to March 28, 2008.

general form of the latent state variables. Researchers have typically found that three factors, often referred to as level, slope, and curvature, are sufficient to account for the time variation in the cross section of nominal Treasury yields (e.g., Litterman and Scheinkman, 1991). This characterization is supported by a principal component analysis of our weekly data set, which consists of Friday observations from January 6, 1995, to March 28, 2008, for eight maturities: three months, six months, one year, two years, three years, five years, seven years, and ten years. ${ }^{4}$ Indeed, as shown in Table 1, 99.9 percent of the total variation in this set of yields is accounted for by the first three principal components. Furthermore, the loadings across the eight maturities for the first component are quite uniform; thus, like a level factor, a shock to this component will change all yields by a similar amount. The second component has negative loadings for short maturities and positive loadings for long ones; thus, like a slope factor, a shock to this component will steepen or flatten the yield curve. Finally, the third component has U-shaped factor loadings as a function of maturity and is naturally interpreted as a curvature factor.

These results help motivate our nominal AFNS model, which assumes that there are

\footnotetext{
${ }^{4}$ Our sample of nominal yields is relatively short because we are persuaded that there have been significant regime shifts in term structure behavior during the postwar period, not least of which stem from changes in the monetary policy rule linking short-term nominal interest rates and inflation. In addition, our sample of real yields is even more limited, rendering earlier data on nominal yields of limited value for our purposes. Our data are obtained from http://www.federalreserve.gov/pubs/feds/2006/index.html and are described in Gürkaynak, Sack, and Wright (2007). These yields are constructed by fitting a zero-coupon yield curve of the Svensson (1994)-type to a large pool of underlying off-the-run Treasury bonds on a daily basis. The authors demonstrate that the model fits the underlying bonds extremely well and, by implication, provides a very good approximation to the Treasury zero-coupon yield curve. Zero-coupon yields for any relevant maturity can be calculated as long as the maturity is within the range of maturities used in the fitting process.
} 
three latent state variables relevant for pricing nominal Treasury yields. The AFNS factors are identified as level, slope, and curvature by imposing the factor loadings from the Nelson and Siegel (1987) yield curve, which is commonly used by financial market practitioners and central banks due to its excellent fit to various real-world yield curves across countries and time; see Bank for International Settlements (2005), Diebold and Li (2006), Gürkaynak, Sack, and Wright (2007), and CDR (2007). CDR show that an AFNS model can closely fit the term structure of interest rates over time and forecasts well out of sample. CDR also show that the AFNS model can be estimated in a straightforward and robust fashion, unlike the canonical maximally flexible affine AF model, which, as noted in the introduction, is plagued with estimation difficulties. ${ }^{5}$

The state vector of the three nominal AFNS model factors - level, slope, and curvature - is denoted as $X_{t}^{N}=\left(L_{t}^{N}, S_{t}^{N}, C_{t}^{N}\right)$. As discussed in CDR, the instantaneous nominal risk-free rate is assumed to be the sum of the level and slope factors:

$$
r_{t}^{N}=L_{t}^{N}+S_{t}^{N}
$$

Also, the dynamics of the state variables under the risk-neutral (or $Q$ ) probability measure are given by the following system of stochastic differential equations:

$$
\left(\begin{array}{c}
d L_{t}^{N} \\
d S_{t}^{N} \\
d C_{t}^{N}
\end{array}\right)=\left(\begin{array}{ccc}
0 & 0 & 0 \\
0 & -\lambda^{N} & \lambda^{N} \\
0 & 0 & -\lambda^{N}
\end{array}\right)\left(\begin{array}{c}
L_{t}^{N} \\
S_{t}^{N} \\
C_{t}^{N}
\end{array}\right) d t+\Sigma^{N}\left(\begin{array}{c}
d W_{t}^{Q, L^{N}} \\
d W_{t}^{Q, S^{N}} \\
d W_{t}^{Q, C^{N}}
\end{array}\right), \quad \lambda^{N}>0
$$

where $W^{Q}$ is a standard Brownian motion in $\mathbf{R}^{3}$ and $\Sigma^{N}$ is the volatility matrix. ${ }^{6}$ An important restriction in this dynamic system is that the factor mean-reversion matrix (under the $Q$-measure) is constrained to take on a very simple form with $\lambda^{N}$ as the only free parameter. ${ }^{7}$ CDR show that this AFNS structure implies that nominal zero-coupon yields with maturity

\footnotetext{
${ }^{5}$ Duffee (2008) describes the difficulties that require "a fairly elaborate hands-on estimation procedure." As an alternative strategy, DKW augment an AF model of nominal and real yields with data on inflation and survey data on forecasts of short-term nominal interest rates. However, adding inflation data to the model raises the thorny issue of reproducing the appropriate real-time information set of investors in light of lagged data releases and ex post data revisions. An advantage of our strategy is that our model only uses data from financial markets. In addition, adding survey data into the estimation raises questions about the congruency between the information sets of survey respondents and financial market participants.

${ }^{6}$ For identification, we fix the mean vector under the $Q$-measure at zero, which CDR show is without loss of generality.

${ }^{7}$ Note that the level factor is a unit-root process under the $Q$-measure. To ensure an arbitrage-free model, we impose an arbitrarily large maximum horizon on the economy, which is common in theoretical finance settings). Alternatively, we could replace the zero in the upper left-hand corner of the mean-reversion matrix with an infinitesimally small coefficient to obtain an arbitrage-free model for an unbounded economy, which is indistinguishable from the AFNS model.
} 
$\tau$ at time $t, y_{t}^{N}(\tau)$, take the form:

$$
y_{t}^{N}(\tau)=L_{t}^{N}+\left(\frac{1-e^{-\lambda^{N} \tau}}{\lambda^{N} \tau}\right) S_{t}^{N}+\left(\frac{1-e^{-\lambda^{N} \tau}}{\lambda^{N} \tau}-e^{-\lambda^{N} \tau}\right) C_{t}^{N}+\frac{A^{N}(\tau)}{\tau}
$$

that is, the three factors are given exactly the same level, slope, and curvature factor loadings in the Nelson-Siegel (1987) yield curve. A shock to $L_{t}^{N}$ affects yields at all maturities uniformly; a shock to $S_{t}^{N}$ affects yields at short maturities more than long ones; and a shock to $C_{t}^{N}$ affects midrange maturities most. The identification of the general role of each factor, even though the factors themselves remain unobserved and the precise factor loadings depend on the estimated $\lambda^{N}$, ensures the estimation of the AFNS model is straightforward and robust - unlike the maximally flexible affine AF model.

The yield function also contains the yield-adjustment term $\frac{A^{N}(\tau)}{\tau}$, which is time-invariant and only depends on the maturity of the bond. CDR provide an analytical formula for this term, which under our identification scheme is entirely determined by the volatility matrix $\Sigma^{N}$. CDR find that allowing for a maximally flexible parameterization of the volatility matrix diminishes out-of-sample forecast performance, so we restrict $\Sigma^{N}$ to be diagonal.

The final element required for empirical implementation of an affine AF model is a specification of the price of risk. For tractable implementation, we employ the popular essentially affine risk premium specification introduced in Duffee (2002), which implies that the price of risk, $\Gamma_{t}$, depends on the state variables:

$$
\Gamma_{t}=\gamma^{0}+\gamma^{1} X_{t}^{N}
$$

where $\gamma^{0} \in \mathbf{R}^{3}$ and $\gamma^{1} \in \mathbf{R}^{3 \times 3}$ are unrestricted. The relationship between real-world yield curve dynamics under the $P$-measure and risk-neutral dynamics under the $Q$-measure is given by the measure change

$$
d W_{t}^{Q}=d W_{t}^{P}+\Gamma_{t} d t
$$

Therefore, we can write the $P$-dynamics of the state variables as

$$
d X_{t}^{N}=K^{P, N}\left(\theta^{P, N}-X_{t}^{N}\right) d t+\Sigma^{N} d W_{t}^{P}
$$

where both $K^{P, N}$ and $\theta^{P, N}$ are allowed to vary freely. ${ }^{8}$

\footnotetext{
${ }^{8}$ The structure under the $Q$-measure places no restrictions on the dynamic drift components under the empirical $P$-measure beyond the requirement of constant volatility. We follow the literature and do not impose the nonstationarity of the level factor under the $P$-measure, even though it is found to be highly persistent. Our empirical results depend on the specification of the model's $P$-dynamics, which would include
} 


\begin{tabular}{|c|ccc||c||c|c|}
\hline$K^{P, N}$ & $K_{\cdot, 1}^{P, N}$ & $K_{\cdot, 2}^{P, N}$ & $K_{\cdot, 3}^{P, N}$ & $\theta^{P, N}$ & & $\Sigma^{N}$ \\
\hline$K_{1, \cdot}^{P, N}$ & 0.100 & -0.068 & 0.0194 & 0.0629 & $\Sigma_{1,1}^{N}$ & 0.00471 \\
& $(0.220)$ & $(0.096)$ & $(0.076)$ & $(0.0071)$ & & $(0.00014)$ \\
$K_{2, \cdot}^{P, N}$ & 1.434 & 0.795 & -0.997 & -0.0219 & $\Sigma_{2,2}^{N}$ & 0.00771 \\
& $(0.515)$ & $(0.187)$ & $(0.163)$ & $(0.0113)$ & & $(0.00021)$ \\
$K_{3, \cdot}^{P, N}$ & -0.757 & 0.177 & 0.736 & -0.0113 & $\Sigma_{3,3}^{N}$ & 0.02844 \\
& $(1.270)$ & $(0.494)$ & $(0.485)$ & $(0.0112)$ & & $(0.00056)$ \\
\hline
\end{tabular}

Table 2: Parameter Estimates for the Nominal AFNS Model.

The estimated parameters of the $K^{P, N}$ matrix, $\theta^{P, N}$ vector, and diagonal $\Sigma^{N}$ matrix are shown for the AFNS model of nominal Treasury bond yields. The estimated value of $\lambda^{N}$ is 0.5242 with a standard deviation of 0.0053 . The maximum log-likelihood value is $32,311.36$. The numbers in parentheses are estimated parameter standard deviations.

We estimate this model using the Kalman filter, as detailed in the appendix. The Kalman filter provides consistent and efficient parameter estimates and easily handles missing data, which will be useful for combining nominal and real yields in the joint estimation. ${ }^{9}$ Table 2 presents the estimated parameters for this model, and Table 3 presents the root-mean-squares of its in-sample, fitted errors. The level factor is very persistent (with a rate of own mean reversion of only 0.100), while the slope and curvature factors revert to their means more quickly. Only a few of the off-diagonal elements in $K^{P, N}$ are significant, which is consistent with earlier work. For example, CDR find better out-of-sample forecast performance from an estimated model with a diagonal rather than an unrestricted $K^{P, N}$ matrix. With the exception of the three-month and ten-year yields, the errors are quite low and indicate a reasonable overall fit to the cross-section of yields. ${ }^{10}$

In this study, we are largely interested in the separate nominal and real models in order to calculate the correlations between the associated nominal and real factors. These factors are essentially insensitive to any restrictions that might be placed on the $K^{P, N}$ matrix, so we simply employ the unrestricted, flexible version in the models. For the joint model, where the estimates of the factor dynamics will affect the resulting decomposition of the BEI rate, we provide a thorough analysis of alternative dynamic specifications.

the imposition of a unit root. The issue of small-sample parameter estimation bias (which would be in the direction of a less persistent process) is an important issue that is yet to be examined in the arbitrage-free term structure literature.

${ }^{9}$ Note that yields at each maturity have their own i.i.d. measurement error within the estimation process.

${ }^{10}$ The three-month maturity is difficult to fit partly because the short end of the Treasury yield curve is buffeted by short-term idiosyncratic forces (Duffee, 1996). 


\begin{tabular}{|c||c|c|}
\hline \multicolumn{1}{|c||}{$\begin{array}{c}\text { Maturity } \\
\text { in months }\end{array}$} & \multicolumn{2}{c|}{ Nominal AFNS model } \\
\hline & Mean & RMSE \\
\hline 3 & -0.16 & 10.31 \\
6 & 0.00 & 0.00 \\
12 & 1.63 & 6.12 \\
24 & 2.18 & 4.07 \\
36 & 0.00 & 0.00 \\
60 & -2.69 & 3.47 \\
84 & 0.22 & 2.37 \\
120 & 10.44 & 12.05 \\
\hline
\end{tabular}

Table 3: Measures of Fit for the Nominal AFNS Model.

The means and root mean squared errors (RMSE) of the fitted errors of the preferred threefactor nominal AFNS model are shown. All numbers are measured in basis points. The nominal yields cover the period from January 6, 1995, to March 28, 2008.

\section{An empirical AFNS model for real yields}

In this section, we estimate an affine AF model for real zero-coupon U.S. Treasury bond yields derived from TIPS yields. ${ }^{11}$ In the empirical literature on term structure modeling, the focus has been on nominal rather than real bond yields in part because of the relative scarcity of real debt. The U.S. Treasury first issued TIPS in 1997, but for several years afterward, the liquidity of the secondary TIPS market was impaired by the small amount of securities outstanding and uncertainty about the Treasury's commitment to the program. Indeed, as described by Roush (2008), secondary TIPS market trading was very low at least into 2002, and DKW estimate that such illiquidity boosted TIPS yields by 1 to 2 percentage points. To avoid spurious quotes from the illiquid nascent years of this market, we begin our sample of TIPS yields in 2003; therefore, our weekly real yield data cover the period from January 3 , 2003, to March 28, 2008, and are measured at the end of business each Friday. In addition, due to the limited maturity range in the TIPS market, we only consider maturities of five, six, seven, eight, nine, and ten years.

Table 4 reports the factor loadings that correspond to the first three principal components for our sample of real yields by maturity. The first two components account for essentially all of the variation in the data, and these components have loadings that are consistent with level and slope interpretations. Given the limited range of available maturities for real yields, it is not surprising that a curvature factor is not needed in this case. Therefore, we estimate an

\footnotetext{
${ }^{11}$ Our data are obtained from the Federal Reserve Board of Governors; see Gürkaynak, Sack, and Wright (2008) and the website http://www.federalreserve.gov/pubs/feds/2008/index.html. Note that the calculation of the real zero-coupon yields is based on both on-the-run and off-the-run TIPS bonds.
} 


\begin{tabular}{|c|c|c|c|}
\hline Maturity & First & Second & Third \\
\hline 60 & -0.5401 & 0.6045 & -0.5141 \\
72 & -0.4700 & 0.2165 & 0.3359 \\
84 & -0.4119 & -0.0644 & 0.4955 \\
96 & -0.3632 & -0.2741 & 0.2823 \\
108 & -0.3219 & -0.4357 & -0.1032 \\
120 & -0.2867 & -0.5645 & -0.5357 \\
\hline \% explained & 0.9708 & 0.0290 & 0.0002 \\
\hline
\end{tabular}

Table 4: First Three Principal Components in Real Yields.

The loadings of yields of various maturities on the first three principal components are shown. The final row shows the proportion of all bond yield variability accounted for by each principal component. The data consist of weekly real zero-coupon bond yields from January 3, 2003, to March 28, 2008.

AFNS model for real yields with a state vector of two factors, denoted as $X_{t}^{R}=\left(L_{t}^{R}, S_{t}^{R}\right) .{ }^{12}$ The instantaneous risk-free real rate is defined as the sum of the level and slope factors; i.e.,

$$
r_{t}^{R}=L_{t}^{R}+S_{t}^{R}
$$

The dynamics of these two factors under the $Q$-measure are given by the stochastic differential equations:

$$
\left(\begin{array}{c}
d L_{t}^{R} \\
d S_{t}^{R}
\end{array}\right)=\left(\begin{array}{cc}
0 & 0 \\
0 & -\lambda^{R}
\end{array}\right)\left(\begin{array}{c}
L_{t}^{R} \\
S_{t}^{R}
\end{array}\right) d t+\Sigma^{R}\left(\begin{array}{c}
d W_{t}^{Q, L^{R}} \\
d W_{t}^{Q, S^{R}}
\end{array}\right), \quad \lambda^{R}>0
$$

where $W^{Q}$ is a standard Brownian motion in $\mathbf{R}^{2}$ and $\Sigma^{R}$ is a diagonal volatility matrix. ${ }^{13}$

By imposing this structure on the general affine model, real zero-coupon yields with maturity $\tau$ at time $t, y_{t}^{R}(\tau)$, are given by

$$
y_{t}^{R}(\tau)=L_{t}^{R}+\left(\frac{1-e^{-\lambda^{R} \tau}}{\lambda^{R} \tau}\right) S_{t}^{R}+\frac{A^{R}(\tau)}{\tau},
$$

which has Nelson-Siegel factor loadings for the level and slope factors and a maturitydependent yield-adjustment term $\frac{A^{R}(\tau)}{\tau}$, as described in CDR. As above, we use a diagonal covariance matrix and the essentially affine risk premium specification:

$$
\Gamma_{t}=\gamma^{0}+\gamma^{1} X_{t}^{R}
$$

\footnotetext{
${ }^{12}$ We also estimated a three-factor real AFNS model, as discussed in the appendix, and found it to be overparameterized.

${ }^{13}$ Again, for identification, we fix the mean vector under the $Q$-measure at zero.
} 


\begin{tabular}{|c|cc||c||c|c|}
\hline$K^{P, R}$ & $K_{\cdot, 1}^{P, R}$ & $K_{\cdot, 2}^{P, R}$ & $\theta^{P, R}$ & & $\Sigma^{R}$ \\
\hline$K_{1, \cdot}^{P, R}$ & 1.565 & 0.223 & 0.0307 & $\Sigma_{1,1}^{R}$ & 0.00535 \\
& $(0.719)$ & $(0.174)$ & $(0.0023)$ & & $(0.00010)$ \\
$K_{2, \cdot}^{P, R}$ & 2.448 & 0.840 & -0.0336 & $\Sigma_{2,2}^{R}$ & 0.0154 \\
& $(2.759)$ & $(0.667)$ & $(0.0140)$ & & $(0.00067)$ \\
\hline
\end{tabular}

Table 5: Parameter Estimates for Real AFNS Model.

The estimated parameters of the $K^{P, R}$ matrix, $\theta^{P, R}$ vector, and diagonal $\Sigma^{R}$ matrix are shown for the AFNS model of TIPS yields. The estimated value of $\lambda^{R}$ is 0.339 with a standard deviation of 0.0033 . The maximum log-likelihood value is $12,359.09$. The numbers in parentheses are estimated parameter standard deviations.

\begin{tabular}{|c||c|c|}
\hline \multicolumn{1}{|c||}{$\begin{array}{c}\text { Maturity } \\
\text { in months }\end{array}$} & \multicolumn{2}{c|}{ Real AFNS model } \\
\hline & Mean & RMSE \\
\hline 60 & 0.93 & 3.85 \\
72 & 0.28 & 1.13 \\
84 & 0.00 & 0.00 \\
96 & -0.06 & 0.23 \\
108 & 0.00 & 0.00 \\
120 & 0.10 & 0.44 \\
\hline
\end{tabular}

Table 6: Measures of Fit for the Real AFNS Model.

The means and root mean squared errors (RMSE) of the fitted errors for the preferred, twofactor real AFNS model are shown. All numbers are measured in basis points. The real TIPS yields cover the period from January 3, 2003 to March 28, 2008.

where $\gamma^{0} \in \mathbf{R}^{2}$ and $\gamma^{1} \in \mathbf{R}^{2 \times 2}$ are unrestricted. Since the same relationship between realworld and risk-neutral dynamics applies here as well, we can express the $P$-dynamics of the state variables as

$$
d X_{t}^{R}=K^{P, R}\left(\theta^{P, R}-X_{t}^{R}\right) d t+\Sigma^{R} d W_{t}^{P}
$$

where both $K^{P, R}$ and $\theta^{P, R}$ are allowed to vary freely.

Table 5 presents the estimated parameters for the dynamics of the two state variables based on the Kalman filter estimation. Both factors revert to their means fairly quickly. The real level factor has an estimated volatility similar to that of the nominal level factor, but the real slope factor is estimated to be twice as volatile as the nominal slope factor. The fitted errors of this real AFNS model are reported in Table 6. Their small size indicates that two factors are sufficient to model the variation in our TIPS yield sample, which is consistent with the principal component analysis. 


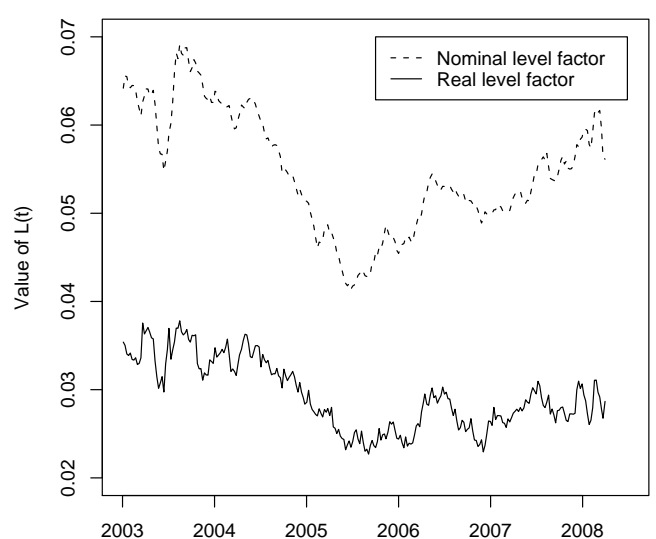

(a) Estimated level factors.

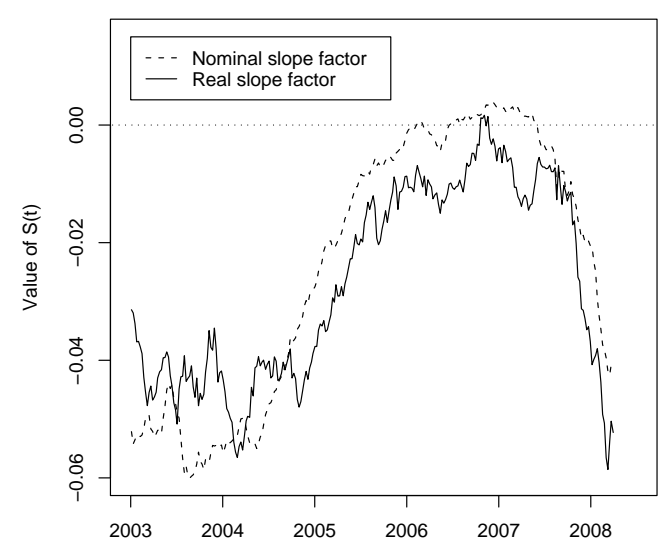

(b) Estimated slope factors.

Figure 1: Estimated Nominal and Real Level and Slope Factors.

The estimated level and slope factors from the two-factor real AFNS model are shown with the level and slope factors from the three-factor nominal AFNS model.

\section{A joint AFNS model for nominal and real yields}

An attractive feature of the AFNS model is that it can be extended to incorporate as many factors as required within a tractable estimation framework. For example, Christensen and Lopez (2008) estimate a joint AFNS model that accounts for the standard three Treasury yield factors and two additional factors accounting for corporate credit spread dynamics. In this section, we estimate a joint AFNS model that combines the separate nominal and real yield models presented above.

Figure 1 compares the estimated paths of the level and slope factors from the two separate AFNS models for nominal and real interest rates. The correlation between the two level factors is 0.90 , while the slope factors have a correlation of 0.92 . Given these high correlations, it is tempting to use just three factors to model the variation in both sets of bond yields; however, as described in the appendix, we found that a three-factor joint AFNS model was too restrictive to fit both nominal and real yields. Instead, we only impose the assumption of a common slope factor across the nominal and real yields. Therefore, our joint model has four factors: a real level factor $\left(L_{t}^{R}\right)$ that is specific to TIPS yields only; a nominal level factor $\left(L_{t}^{N}\right)$ for nominal yields; and common slope and curvature factors. (The curvature factor, of course, is only needed for fitting the nominal yields.)

The state vector of joint AFNS model factors is denoted as $X_{t}^{J}=\left(L_{t}^{N}, S_{t}, C_{t}, L_{t}^{R}\right)$, and 
the instantaneous nominal and real risk-free rates are defined by:

$$
\begin{aligned}
& r_{t}^{N}=L_{t}^{N}+S_{t}, \\
& r_{t}^{R}=L_{t}^{R}+\alpha^{R} S_{t} .
\end{aligned}
$$

The differential scaling of real rates to the common slope factor is captured by the parameter $\alpha^{R}$. The nominal yield curve is generally upward-sloping as evidenced by the negative value of the nominal slope factor presented in Figure 1(b). Based on the modeling assumptions summarized in Equations 11 and 12, the implied positive term premium is imposed on the real yield curve as well.

To preserve the Nelson-Siegel factor loading structure in the nominal yield function, the $Q$-dynamics of the state variables are given by the stochastic differential equations:

$$
\left(\begin{array}{c}
d L_{t}^{N} \\
d S_{t} \\
d C_{t} \\
d L_{t}^{R}
\end{array}\right)=\left(\begin{array}{cccc}
0 & 0 & 0 & 0 \\
0 & -\lambda & \lambda & 0 \\
0 & 0 & -\lambda & 0 \\
0 & 0 & 0 & 0
\end{array}\right)\left(\begin{array}{c}
L_{t}^{N} \\
S_{t} \\
C_{t} \\
L_{t}^{R}
\end{array}\right) d t+\Sigma^{J}\left(\begin{array}{c}
d W_{t}^{Q, L^{N}} \\
d W_{t}^{Q, S} \\
d W_{t}^{Q, C} \\
d W_{t}^{Q, L^{R}}
\end{array}\right)
$$

Based on these dynamics, nominal Treasury zero-coupon yields are

$$
y_{t}^{N}(\tau)=L_{t}^{N}+\left(\frac{1-e^{-\lambda \tau}}{\lambda \tau}\right) S_{t}+\left(\frac{1-e^{-\lambda \tau}}{\lambda \tau}-e^{-\lambda \tau}\right) C_{t}+\frac{A^{N}(\tau)}{\tau}
$$

and real zero-coupon yields are

$$
y_{t}^{R}(\tau)=L_{t}^{R}+\alpha^{R}\left(\frac{1-e^{-\lambda \tau}}{\lambda \tau}\right) S_{t}+\alpha^{R}\left(\frac{1-e^{-\lambda \tau}}{\lambda \tau}-e^{-\lambda \tau}\right) C_{t}+\frac{A^{R}(\tau)}{\tau} .
$$

Again, details regarding the yield-adjustment terms are presented in CDR. Using the essentially affine risk premium specification, the implied measure change is given by

$$
d W_{t}^{Q}=d W_{t}^{P}+\Gamma_{t} d t
$$

where $\Gamma_{t}=\gamma^{J, 0}+\gamma^{J, 1} X_{t}^{J}, \gamma^{J, 0} \in \mathbf{R}^{4}$, and $\gamma^{J, 1} \in \mathbf{R}^{4 \times 4}$. The resulting four-factor AFNS model has $P$-dynamics given by

$$
\left(\begin{array}{c}
d L_{t}^{N} \\
d S_{t} \\
d C_{t} \\
d L_{t}^{R}
\end{array}\right)=\left(\begin{array}{cccc}
\kappa_{11}^{P, J} & \kappa_{12}^{P, J} & \kappa_{13}^{P, J} & \kappa_{14}^{P, J} \\
\kappa_{21}^{P, J} & \kappa_{22}^{P, J} & \kappa_{23}^{P, J} & \kappa_{24}^{P, J} \\
\kappa_{31}^{P, J} & \kappa_{32}^{P, J} & \kappa_{33}^{P, J} & \kappa_{34}^{P, J} \\
\kappa_{41}^{P, J} & \kappa_{42}^{P, J} & \kappa_{43}^{P, J} & \kappa_{44}^{P, J}
\end{array}\right)\left(\left(\begin{array}{c}
\theta_{1}^{P, J} \\
\theta_{2}^{P, J} \\
\theta_{3}^{P, J} \\
\theta_{4}^{P, J}
\end{array}\right)-\left(\begin{array}{c}
L_{t}^{N} \\
S_{t} \\
C_{t} \\
L_{t}^{R}
\end{array}\right)\right) d t+\Sigma^{J}\left(\begin{array}{c}
d W_{t}^{P, L^{N}} \\
d W_{t}^{P, S} \\
d W_{t}^{P, C} \\
d W_{t}^{P, L^{R}}
\end{array}\right),
$$




\begin{tabular}{|l|c|c|c|c|c|}
\hline Alternative & \multicolumn{5}{|c|}{ Goodness of fit statistics } \\
\cline { 2 - 6 } Specifications & $\log L$ & $k$ & $p$-value & AIC & BIC \\
\hline (1) Unrestricted $K^{P, J}$ & 42304.5 & 40 & - & -84529.0 & -84347.5 \\
$(2) \kappa_{31,}^{P, J}=0$ & 42304.5 & 39 & 0.89 & -84531.0 & -84354.0 \\
$(3) \kappa_{31}^{P, J}=\kappa_{12}^{P, J}=0$ & 42304.4 & 38 & 0.65 & -84532.8 & -84360.4 \\
$(4) \kappa_{31}^{P, J}=\kappa_{12}^{P, J}=\kappa_{32}^{P, J}=0$ & 42304.3 & 37 & 0.67 & -84534.6 & -84366.7 \\
$(5) \kappa_{31}^{P, J}=\ldots=\kappa_{34}^{P, J}=0$ & 42303.9 & 36 & 0.37 & -84535.8 & -84372.5 \\
$(6) \kappa_{31}^{P, J}=\ldots=\kappa_{13}^{P, J}=0$ & 42303.8 & 35 & 0.58 & -84537.5 & -84378.7 \\
$(7) \kappa_{31}^{P, J}=\ldots=\kappa_{43}^{P, J}=0$ & 42303.6 & 34 & 0.53 & -84539.1 & -84384.8 \\
$(8) \kappa_{31}^{P, J}=\ldots=\kappa_{24}^{P, J}=0$ & 42303.2 & 33 & 0.40 & $\mathbf{- 8 4 5 4 0 . 4}$ & -84390.6 \\
$(9) \kappa_{31}^{P, J}=\ldots=\kappa_{41}^{P, J}=0$ & 42301.3 & 32 & 0.06 & -84538.7 & $\mathbf{- 8 4 3 9 3 . 5}$ \\
$(10) \kappa_{31}^{P, J}=\ldots=\kappa_{42}^{P, J}=0$ & 42296.1 & 31 & $<0.01$ & -84530.2 & -84389.6 \\
$(11) \kappa_{31}^{P, J}=\ldots=\kappa_{21}^{P, J}=0$ & 42285.6 & 30 & $<0.01$ & -84511.2 & -84375.0 \\
$(12) \kappa_{31}^{P, J}=\ldots=\kappa_{14}^{P, J}=0$ & 42277.0 & 29 & $<0.01$ & -84496.0 & -84364.4 \\
$(13) \kappa_{31}^{P, J}=\ldots=\kappa_{23}^{P, J}=0$ & 42253.8 & 28 & $<0.01$ & -84451.5 & -84324.5 \\
\hline
\end{tabular}

Table 7: Evaluation of Alternative Specifications of Joint AFNS Model.

Thirteen alternative estimated specifications of the joint AFNS model are evaluated. Each specification is listed with its $\log$ likelihood $(\log L)$, number of parameters $(k)$, the $p$-value from a likelihood ratio test of the hypothesis that the specification differs from the one directly above that has one more free parameter. The information criteria (AIC and BIC) are also reported, and their minimum values are given in boldface.

where $\Sigma^{J}$ is diagonal.

As alluded to earlier, the specification of the $P$-dynamics is an important element in determining the model's decomposition of BEI rates into inflation expectations and risk premiums. Therefore, we conduct a careful evaluation of various model specifications, as summarized in Table 7. The first column of this table describes the 13 alternative specifications considered. Specification (1) at the top corresponds to an unrestricted $4 \times 4$ mean-reversion matrix $K^{P, J}$, which provides maximum flexibility in fitting the data. We then pare down this matrix using a general-to-specific strategy that restricts the least significant parameter (as measured by ratio of the parameter value to its standard error) to zero and then re-estimate the model. Therefore, specification (2) sets $\kappa_{31}^{P, J}=0$, so it has one fewer estimated parameters. Specification (3) sets this parameter and $\kappa_{32}^{P, J}$ both equal to zero. This strategy of eliminating the least significant coefficients continues to the final specification (13), which has a diagonal $K^{P, J}$ matrix.

Each estimated specification is listed with its $\log$ likelihood $(\log L)$, its number of estimated parameters $(k)$, and the $p$-value from a likelihood ratio test of the hypothesis that it differs from the specification with one more free parameter - that is, comparing specification 
$(s)$ with specification $(s-1)$. We also report two information criteria commonly used for model selection: the Akaike information criterion, which is defined as $A I C=-2 \log L+2 k$, and the Bayes information criterion, which is defined as $B I C=-2 \log L+k \log T$, where $T$ is the number of data observations (see e.g., Harvey, 1989). ${ }^{14}$ These information criteria are minimized by specifications (8) and (9) (the boldface entries in the rightmost columns), which are thus our favored models. Notably, the unrestricted specification (1) appears overparameterized, and the diagonal specification (13) appears too parsimonious. The likelihood ratio test also suggests that (at the 10-percent level) specification (8) is a parsimonious model that still provides as good a fit to the data as the maximally flexible unrestricted specification. Therefore, we select specification (8) as our preferred joint AFNS model.

Table 8 contains the estimated parameters for the preferred specification (8). Note that the off-diagonal elements in the estimated $K^{P, J}$ matrix (excluding the seven zero restrictions) are highly statistically significant. The mean and volatility parameters for the three nominal factors and the estimated value of $\lambda$ are very similar to those reported in Table 2 for the threefactor nominal AFNS model. Based on these results, we anticipate the fit of the nominal yields and the estimated paths of the three nominal yield risk factors to be very similar across these two models. Indeed, as shown in Table 9, which contains summary statistics for the fitted errors of the joint model, there is no discernible difference in fit between the joint model and the nominal model for the eight maturities of nominal yields, as reported in Table 3 . Table 9 does report a worse fit of the joint model relative to the two-factor model for real yields, as reported in Table 6. However, the difference in fit appears to be acceptable since the correlation between the estimated real level factors from the joint and real AFNS models is 0.86 . The correlation between the estimated real slope factor from the real AFNS model and the joint AFNS model-implied real slope factor (i.e., $\alpha^{R} S_{t}$ ) is 0.92 . The high correlations between these factors provide further support for the joint model.

\section{$5 \quad$ Inflation expectations and inflation risk premiums}

In this section, we decompose the BEI rates into inflation expectations and inflation risk premiums. We start with a theoretical discussion of how an AF model of nominal and real yields can produce this decomposition, and then we present the empirical decomposition provided by our estimated joint AFNS model.

\footnotetext{
${ }^{14}$ We have 691 nominal yield and 273 real yield weekly observations. We interpret $T$ as referring to the longest data series and fix it at 691 .
} 


\begin{tabular}{|l|cccc||c||c|c|}
\hline$K^{P, J}$ & $K_{., 1}^{P, J}$ & $K_{\cdot, 2}^{P, J}$ & $K_{., 3}^{P, J}$ & $K_{., 4}^{P, J}$ & $\theta^{P, J}$ & & $\Sigma^{J}$ \\
\hline$K_{1, \cdot}^{P, J}$ & 1.298 & 0 & 0 & -1.510 & 0.06312 & $\Sigma_{1,1}^{J}$ & 0.00446 \\
& $(0.279)$ & & & $(0.487)$ & $(0.00112)$ & & $(0.00016)$ \\
$K_{2, .}^{P, J}$ & 1.561 & 0.828 & -1.044 & 0 & -0.02032 & $\Sigma_{2,2}^{J}$ & 0.00755 \\
& $(0.497)$ & $(0.164)$ & $(0.141)$ & & $(0.00857)$ & & $(0.00023)$ \\
$K_{3, \cdot}^{P, J}$ & 0 & 0 & 0.883 & 0 & -0.01006 & $\Sigma_{3,3}^{J}$ & 0.02920 \\
& & & $(0.380)$ & & $(0.00649)$ & & $(0.00057)$ \\
$K_{4, \cdot}^{P, J}$ & -1.640 & -0.367 & 0 & 1.651 & 0.03536 & $\Sigma_{4,4}^{J}$ & 0.00412 \\
& $(0.650)$ & $(0.111)$ & & $(0.714)$ & $(0.00253)$ & & $(0.00014)$ \\
\hline
\end{tabular}

Table 8: Parameter Estimates for Joint AFNS Model.

The estimated parameters of the $K^{P, J}$ matrix, $\theta^{P, J}$ vector, and diagonal $\Sigma^{J}$ matrix are shown for the AFNS model of nominal and real yields. The estimated value of $\lambda$ is 0.5313 with a standard deviation of 0.0052 , while $\alpha^{R}$ is estimated to be 0.7072 with a standard deviation of 0.0066 . The numbers in parentheses are the estimated parameter standard deviations.

\begin{tabular}{|c||c|c|}
\hline \multicolumn{1}{|c||}{$\begin{array}{c}\text { Maturity } \\
\text { in months }\end{array}$} & \multicolumn{2}{c|}{ Joint AFNS model } \\
\hline Nom. yields & Mean & RMSE \\
\hline 3 & -0.25 & 10.31 \\
6 & 0.00 & 0.00 \\
12 & 1.74 & 6.16 \\
24 & 2.28 & 4.16 \\
36 & 0.00 & 0.00 \\
60 & -2.89 & 3.87 \\
84 & -0.12 & 2.94 \\
120 & 9.95 & 11.46 \\
\hline TIPS yields & Mean & RMSE \\
\hline 60 & -4.03 & 10.15 \\
72 & -2.25 & 6.55 \\
84 & -0.98 & 3.17 \\
96 & 0.00 & 0.00 \\
108 & 0.77 & 2.91 \\
120 & 1.37 & 5.50 \\
\hline
\end{tabular}

Table 9: Measures of Fit for the Joint AFNS Model.

The means and root mean squared errors (RMSE) of the fitted errors for the joint, four-factor AFNS model are shown. All numbers are measured in basis points. The nominal yields cover the period from January 6, 1995, to March 28, 2008, while the real TIPS yields cover the period from January 3, 2003, to March 28, 2008.

\subsection{Theoretical discussion}

To describe the connections among nominal and real yields and inflation within our modeling framework, it is convenient to work in continuous time; see Cochrane (2001) for a primer. We first define the nominal and real stochastic discount factors, denoted $M_{t}^{N}$ and $M_{t}^{R}$, re- 
spectively. The no-arbitrage condition enforces a consistency of pricing for any security over time. Specifically, the price of a nominal bond that pays one dollar at time $\tau$ and the price of a real bond that pays one unit of the consumption basket at time $\tau$ must satisfy

$$
P_{t}^{N}(\tau)=E_{t}^{P}\left[\frac{M_{t+\tau}^{N}}{M_{t}^{N}}\right] \quad \text { and } \quad P_{t}^{R}(\tau)=E_{t}^{P}\left[\frac{M_{t+\tau}^{R}}{M_{t}^{R}}\right]
$$

Given their payment structure, the no-arbitrage condition also requires a consistency between the prices of real and nominal bonds such that the price of the consumption basket, denoted as the overall price level $Q_{t}$, is the ratio of the nominal and real stochastic discount factors:

$$
Q_{t}=\frac{M_{t}^{R}}{M_{t}^{N}}
$$

We assume that the nominal and real stochastic discount factors have the standard dynamics given by

$$
\begin{aligned}
d M_{t}^{N} / M_{t}^{N} & =-r_{t}^{N} d t-\Gamma_{t}^{\prime} d W_{t}^{P}, \\
d M_{t}^{R} / M_{t}^{R} & =-r_{t}^{R} d t-\Gamma_{t}^{\prime} d W_{t}^{P} .
\end{aligned}
$$

By Ito's lemma, the dynamic evolution of $Q_{t}$ is given by

$$
\begin{aligned}
d Q_{t} & \left.=\frac{1}{M_{t}^{N}} d M_{t}^{R}-\frac{M_{t}^{R}}{\left(M_{t}^{N}\right)^{2}} d M_{t}^{N}+\frac{1}{2}\left(\begin{array}{ll}
d M_{t}^{R} & d M_{t}^{N}
\end{array}\right)\left(\begin{array}{cc}
0 & -\frac{1}{\left(M_{t}^{N}\right)^{2}} \\
-\frac{1}{\left(M_{t}^{N}\right)^{2}} & 2 \frac{M_{t}}{\left(M_{t}^{N}\right)^{3}}
\end{array}\right)\left(\begin{array}{c}
d M_{t}^{R} \\
d M_{t}^{N}
\end{array}\right) 22\right) \\
& =\left(r_{t}^{N}-r_{t}^{R}\right) Q_{t} d t
\end{aligned}
$$

With the absence of arbitrage, the instantaneous growth rate of the price level is equal to the difference between the instantaneous nominal and real risk-free rates. (Note that there is no risk premium for the instantaneous rates, and the Fisher equation applies.) Furthermore, by Ito's lemma,

$$
d \ln \left(Q_{t}\right)=\frac{1}{Q_{t}} d Q_{t}-\frac{1}{2} \frac{1}{Q_{t}^{2}} d Q_{t}^{2}=\left(r_{t}^{N}-r_{t}^{R}\right) d t .
$$

By integrating both sides and taking exponentials, we can express the price level at time $t+\tau$ as

$$
Q_{t+\tau}=Q_{t} e^{\int_{t}^{t+\tau}\left(r_{s}^{N}-r_{s}^{R}\right) d s}
$$

The connection between nominal and real zero-coupon yields and expected inflation can 
be readily expressed. Namely, we decompose the price of the nominal zero-coupon bond as

$$
\begin{aligned}
P_{t}^{N}(\tau) & =E^{P}\left[\frac{M_{t+\tau}^{N}}{M_{t}^{N}}\right] \\
& =E^{P}\left[\frac{M_{t+\tau}^{R} / Q_{t+\tau}}{M_{t}^{R} / Q_{t}}\right]=E^{P}\left[\frac{M_{t+\tau}^{R}}{M_{t}^{R}} \frac{Q_{t}}{Q_{t+\tau}}\right] \\
& =E^{P}\left[\frac{M_{t+\tau}^{R}}{M_{t}^{R}}\right] \times E^{P}\left[\frac{Q_{t}}{Q_{t+\tau}}\right]+\operatorname{cov}\left[\frac{M_{t+\tau}^{R}}{\left.M_{t}^{R}, \frac{Q_{t}}{Q_{t+\tau}}\right]}\right. \\
& =E^{P}\left[\frac{M_{t+\tau}^{R}}{M_{t}^{R}}\right] \times E^{P}\left[\frac{Q_{t}}{Q_{t+\tau}}\right] \times\left(1+\frac{\operatorname{cov}\left[\frac{M_{t+\tau}^{R}}{M_{t}^{R}}, \frac{Q_{t}}{Q_{t+\tau}}\right]}{E^{P}\left[\frac{M_{t+\tau}^{R}}{M_{t}^{R}}\right] \times E^{P}\left[\frac{Q_{t}}{Q_{t+\tau}}\right]}\right) .
\end{aligned}
$$

Converting this price into a yield-to-maturity, we obtain

$$
y_{t}^{N}(\tau)=y_{t}^{R}(\tau)+\pi_{t}^{e}(\tau)+\phi_{t}(\tau)
$$

where the market-implied rate of inflation expected at time $t$ from the period $t$ to $t+\tau$ is

$$
\pi_{t}^{e}(\tau)=-\frac{1}{\tau} \ln E^{P}\left[\frac{Q_{t}}{Q_{t+\tau}}\right]=-\frac{1}{\tau} \ln E_{t}^{P}\left[e^{-\int_{t}^{t+\tau}\left(r_{s}^{N}-r_{s}^{R}\right) d s}\right]
$$

and the corresponding inflation risk premium is

$$
\phi_{t}(\tau)=-\frac{1}{\tau} \ln \left(1+\frac{\operatorname{cov}\left[\frac{M_{t+\tau}^{R}}{M_{t}^{R}}, \frac{Q_{t}}{Q_{t+\tau}}\right]}{E^{P}\left[\frac{M_{t+\tau}^{R}}{M_{t}^{R}}\right] \times E^{P}\left[\frac{Q_{t}}{Q_{t+\tau}}\right]}\right) .
$$

This last equation highlights that the inflation risk premium can be positive or negative. It will be positive if and only if

$$
\operatorname{cov}\left[\frac{M_{t+\tau}^{R}}{M_{t}^{R}}, \frac{Q_{t}}{Q_{t+\tau}}\right]<0 .
$$

That is, the riskiness of nominal bonds depends on the covariance between the real stochastic discount factor and inflation. We observe positive inflation risk premiums if the real discount factor tends to be high (i.e., in a structural model, marginal utility is high) at the same time that price inflation is high (i.e., purchasing power is low). ${ }^{15}$

Finally, the BEI rate for maturity $\tau$ at time $t$ is defined as

$$
B E I_{t}(\tau) \equiv y_{t}^{N}(\tau)-y_{t}^{R}(\tau)=\pi_{t}^{e}(\tau)+\phi_{t}(\tau) .
$$

\footnotetext{
${ }^{15}$ See Campbell et al. (2009) for a description of the underlying economic forces that determine the signs of the nominal and real risk premiums.
} 


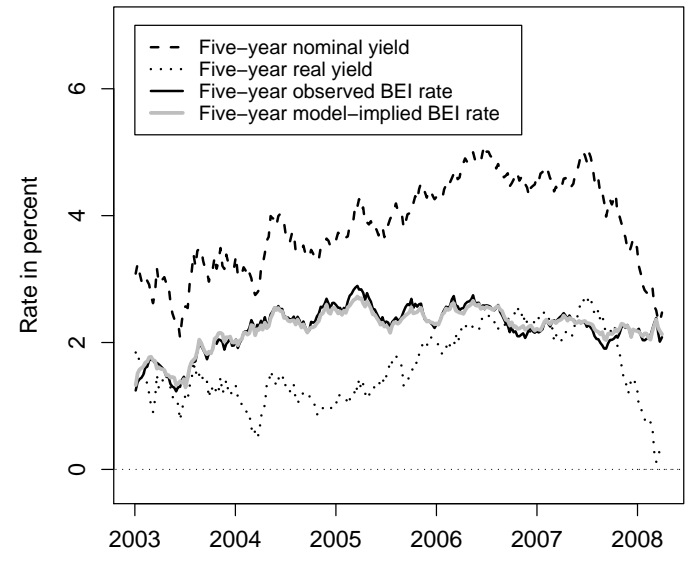

(a) Five-year maturity

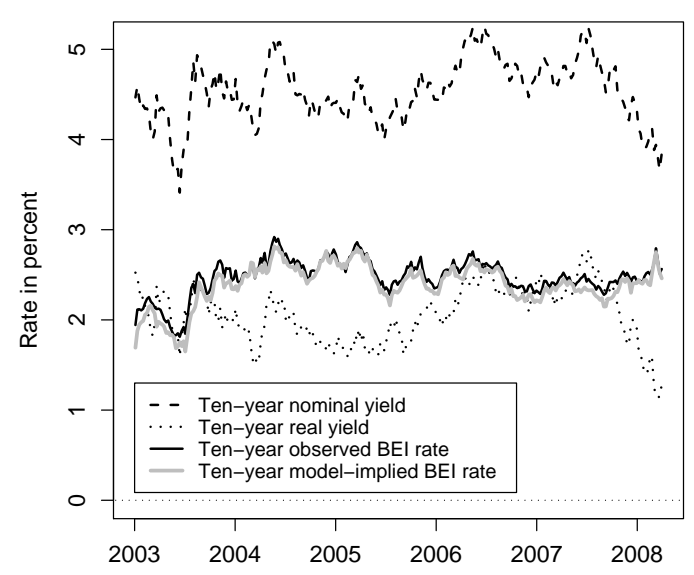

(b) Ten-year maturity

Figure 2: Nominal and Real Yields and BEI Rates.

Data on five- and ten-year nominal and real zero-coupon Treasury yields are plotted with the associated BEI rates and the implied BEI rates from the joint AFNS model.

Namely, the BEI rate is the difference between nominal and real yields and can be decomposed into the sum of expected inflation and the inflation risk premium.

\subsection{Empirical results}

For our joint model estimated on weekly data from January 1995 through March 2008, Figure 2 shows the five- and ten-year nominal and real zero-coupon yields and their differences-i.e., the associated observed BEI rates. Both the five- and ten-year BEI rates increased a bit during the first two years of our sample, but since 2004, they have changed little on balance. Figure 2 also compares these observed BEI rates to comparable-maturity model-implied BEI rates, which are calculated as the differences between the fitted nominal and real yields from the estimated joint AFNS model. The small differences between the observed and model-implied BEI rates reflect the overall good fit of the model.

The joint AFNS model also allows us to decompose the BEI rate into inflation expectations and the inflation risk premia at various horizons. Given the estimated parameters in Table 8 and the estimated paths of the four state variables, the model-implied average five- and tenyear expected inflation series are illustrated in Figure 3. The five-year measure varied from 1.93 percent to 2.54 percent, and the ten-year measure from 2.15 percent to 2.40 percent. These ranges suggest that long-run inflation expectations were fairly well-anchored during our sample period. 


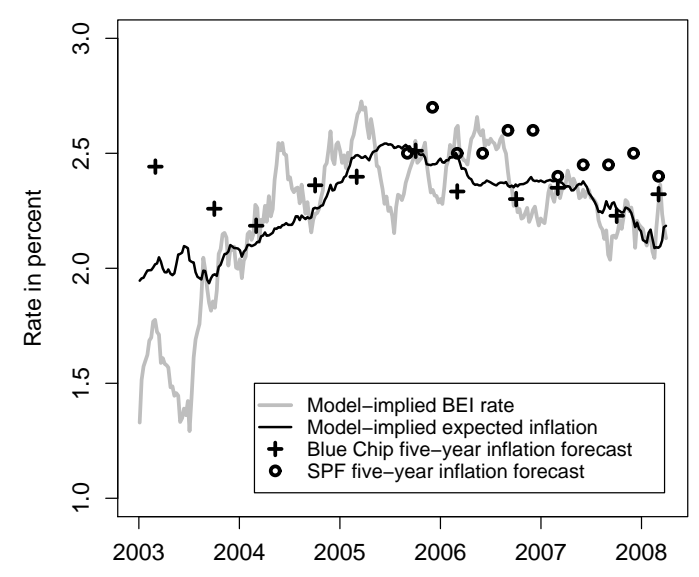

(a) Five-year horizon.

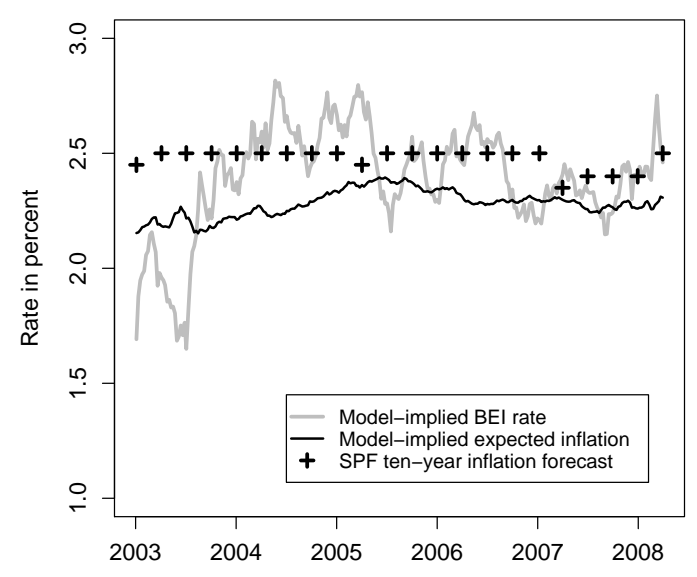

(b) Ten-year horizon.

Figure 3: BEI Rates and Expected Inflation.

The five- and ten-year BEI rates and average expected inflation rates that are implied from the joint AFNS model are plotted along with survey-based measures of inflation expectations.

The model's measures of inflation expectations are generated using only nominal and real yields without any data on inflation or inflation expectations. To provide some independent indication of accuracy, Figure 3 also plots survey-based measures of long-term expectations of CPI inflation, which are obtained from the Blue Chip Consensus survey at the five-year horizon and from the Survey of Professional Forecasters at the five- and ten-year horizon. ${ }^{16}$ The relatively close match between the model-implied and the survey-based measures of inflation expectations provides further support for the model's decomposition of the BEI rate. Note that the largest differences in Figure 3 occur for the five-year horizon during the first half of 2003 with the model-implied measure well below the survey-based one. This pattern is consistent with some remaining residual liquidity deficiencies in the TIPS market, which would hold down bond prices, boost real yields, and lead to an understatement of model-implied inflation expectations.

The $K^{P, J}$ matrix, which governs factor dynamics, plays a key role in the decomposition of BEI rates. The dependence of model-implied inflation expectations on the specification of the $K^{P, J}$ matrix is illustrated in Figure 4, which shows five- and ten-year expected inflation implied by three different specifications of the joint AFNS model. The solid line is the

\footnotetext{
${ }^{16}$ Please note that although the Blue Chip Economic Forecasts reports monthly forecasts of inflation over the upcoming four to five quarters, the five-year inflation forecasts are only reported on a semi-annual basis; particularly, in March and October. The five- and ten-year forecasts from the Survey of Professional Forecasters is reported on a quarterly basis.
} 


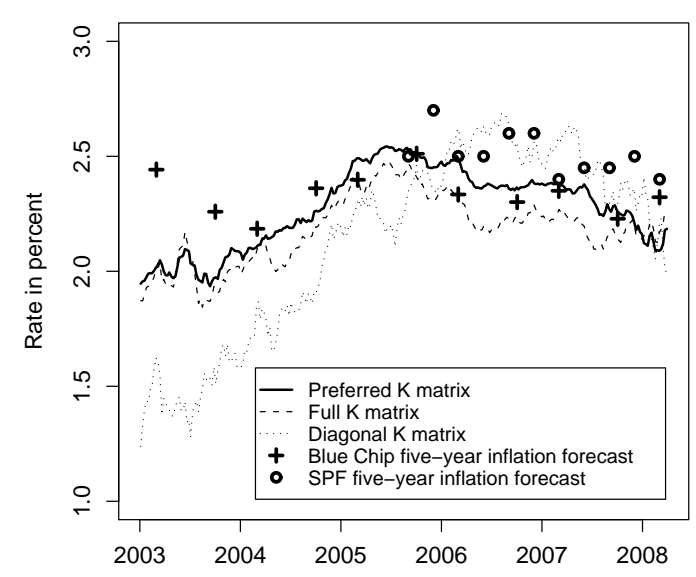

(a) Five-year expected inflation

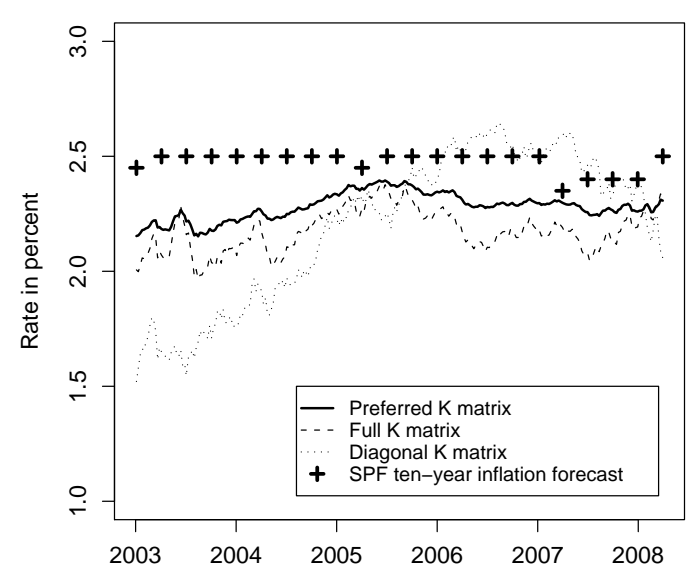

(b) Ten-year expected inflation

Figure 4: Expected Inflation Implied by Alternative Specifications.

Model-implied inflation expectations at the five- and ten-year horizons are shown for our joint AFNS model with the preferred specification of the $K^{P, J}$ matrix, with an unrestricted full $K^{P, J}$ matrix, and with a diagonal $K^{P, J}$ matrix.

preferred specification described earlier, and the dashed and dotted lines are based on the unrestricted and diagonal $K^{P, J}$ matrices, respectively. The preferred specification, which was selected based on in-sample fit to the data, also provides about the closest match to the survey-based inflation forecasts.

Finally, for our preferred specification, we subtract each model-implied expected inflation rate from the comparable-maturity model-implied BEI rate and obtain the associated inflation risk premium (IRP). At both the five- and ten-year horizons, these premiums are fairly small, as shown in Figure 5. ${ }^{17}$ Indeed, during our sample, these inflation premiums have varied in a range around zero of about \pm 50 basis points. ${ }^{18}$

\subsection{Comparison to the literature}

Our results can be usefully compared to the findings of three recent papers in the literature that also decompose U.S. BEI rates using empirical affine AF models of nominal and real yields. The earliest of these studies is by Chen, Liu, and Cheng (2005), who estimated a

\footnotetext{
${ }^{17}$ This result provides some support for the argument that the gain to the U.S. Treasury from issuing TIPS bonds instead of nominal bonds may be quite limited, as argued in Sack and Elsasser (2004).

${ }^{18}$ Again, in theory, the sign of the inflation risk premium depends on the covariance between the real stochastic discount factor and inflation, but there are real-world considerations as well. For example, a liquidity premium for holding TIPS instead of nominal Treasury bonds would show up as a negative inflation risk premium.
} 


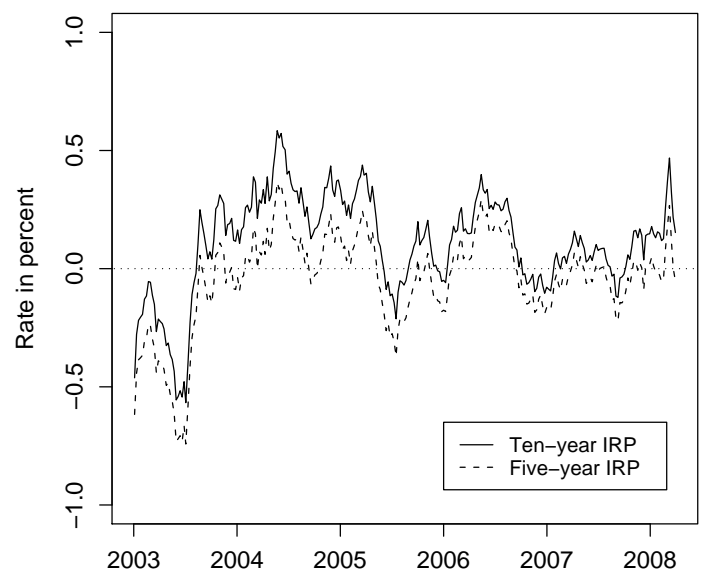

Figure 5: Model-Implied Inflation Risk Premiums.

The five- and ten-year inflation risk premiums (IRP) that are implied from the joint AFNS model are plotted.

two-factor AF model using the weekly nominal and TIPS yields data from January 1998 to December 2004. Their estimated inflation risk premiums are quite stable. The five-year premium averaged about 14 basis points, which is slightly above our estimate. In contrast, their ten-year premium averaged around 130 basis points, which is much higher than our estimate (even for only the two years of overlap between our respective estimation samples for real yields). However, their model estimates are likely influenced by the use of the TIPS yields data from 1998 through 2002, when the market exhibited little volume and poor liquidity.

As in our analysis, two of the other recent U.S. studies also discard these earlier readings on TIPS yields. Specifically, Hördahl and Tristani (2008) decompose BEI rates using an AF macro-finance model that incorporates monthly data on nominal yields, real yields (since 2003), inflation, the output gap, and survey forecasts of inflation and the three-month interest rate. Similar to our results, they find that the ten-year inflation risk premium over the past several years fluctuates mainly within a band of \pm 50 basis points around zero. Of course, one of the distinguishing features of our analysis is that it uses a "yields-only" specification, which provides a market-based reading of inflation expectations that is separate from survey readings or inflation data.

DKW also decompose BEI rates with an affine AF model. Their estimation uses weekly data from the nominal Treasury yield curve, weekly data from the real TIPS yield curve (since 2005), monthly data on inflation, and monthly survey forecasts of short-term nominal interest 
rates and inflation. Figure 6(a) compares their estimated five- and ten-year inflation expectations based on their preferred model, which includes TIPS yields, to our AFNS results. ${ }^{19}$ The average values for their five- and ten-year inflation expectation measures over our sample period from January 2003 through March 2008 are 2.40 percent and 2.39 percent, respectively, which are similar to our values of 2.28 percent and 2.30 percent, respectively. Note, however, that their inflation expectation measures have almost identical dynamics, which is in contrast to our measures. Their results likely reflect the use of a single factor to capture the levels of both nominal and real Treasury yields, while our model uses separate level factors.

In addition, the dynamics of the two sets of inflation measures are quite different. The correlation coefficients between the DKW and AFNS measures are +0.14 for the five-year horizon and -0.27 for the ten-year horizon. The DKW inflation measures do not seem to match the survey measures of inflation expectations very well, even though their models include both inflation and survey data. The correlation between the DKW and survey measures of five-year inflation expectations is -0.08 , while our AFNS and the survey measures have a correlation of 0.40. We can also compare our inflation risk premiums to the DKW estimates, as shown in Figure 6(b). The unconditional means for the AFNS five- and ten-year inflation risk premiums measures are both about -5 basis points, while for the DKW measures, these means are 36 and 64 basis points, respectively. In addition to these differences in unconditional moments, the correlation coefficients between the AFNS and DKW measures of inflation risk premiums are relatively low at 0.25 and 0.38 , at the five- and ten-year horizons, respectively.

\section{Analysis of the recent financial crisis}

The analysis above ends in March 2008 and does not encompass the period of extraordinary financial market stress experienced after the Lehman Brothers investment bank bankruptcy in September 2008. In this section, we first describe the severe financial market dislocations and illiquidity during this period as evident, for example, in reduced trading volume. We then we use our joint AFNS model of nominal and real Treasury yields to examine inflation expectations over the period from Janury 2008 through December 2009. We take advantage of the model's ease of estimation and "yields-only" data requirement to conduct essentially a real-time, out-of-sample analysis over this period. Not surprisingly, this episode of financial and economic turmoil is a very challenging one to fit and interpret.

\footnotetext{
${ }^{19}$ We thank Min Wei for sharing their results with us.
} 


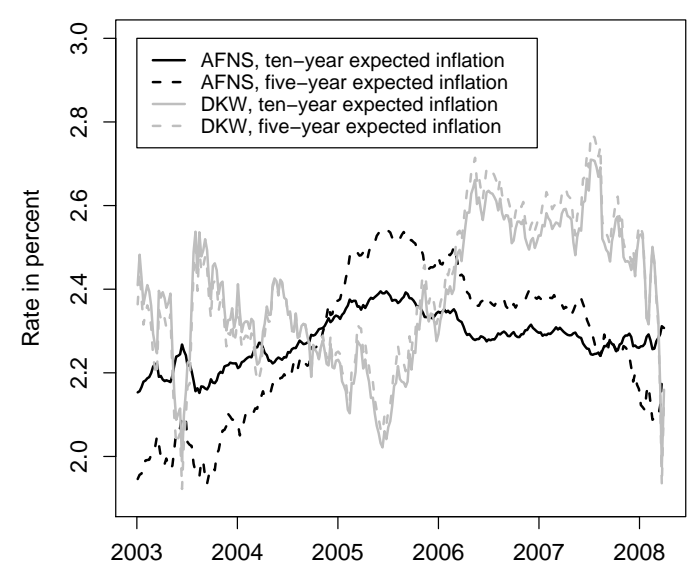

(a) Model-implied inflation expectations.

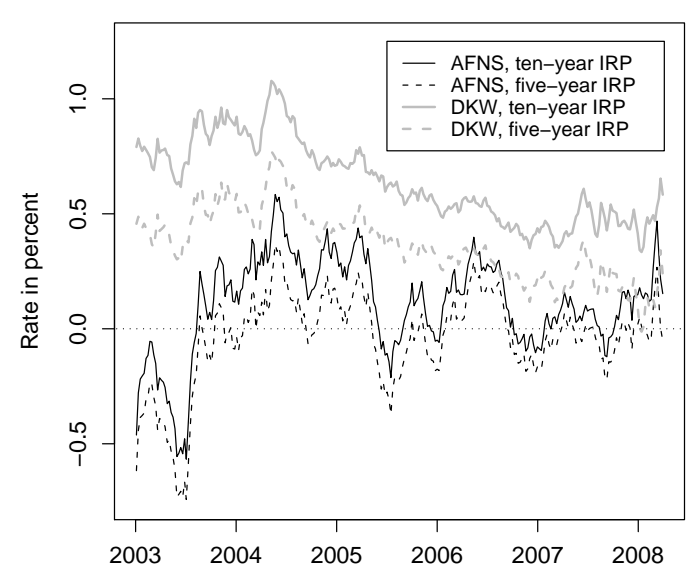

(b) Model-implied IRP.

Figure 6: Model-Implied Inflation Expectations and Risk Premiums.

Model-implied inflation expectations and inflation risk premiums (IRP) at the five-and tenyear horizons are shown for our joint AFNS model and the DKW model.

\subsection{The financial crisis and the Treasury market}

The financial crisis began in August 2007, but it was the bankruptcy of Lehman Brothers in September 2008 that triggered the most severe financial market repercussions. After the failure of Lehman Brothers, fears of credit and liquidity risks jumped, and many financial markets, including equity and currency markets, encountered intense selling pressure as hedge funds and other institutions attempted to shore up their shrinking balance sheets and cover redemptions. Several asset classes faced impaired liquidity with widening bid-ask spreads, lower trading volume, and a concurrent increase in yields. The jump in risk aversion also helped create a heightened global demand for safe assets, and this "flight-to-quality" (or "safe haven") demand favored highly liquid nominal Treasury securities and led to a sharp decline in their yields (see Campbell et al., 2009). As shown in Figure 7, from September 12 (the Friday before the Lehman bankruptcy) through the end of 2008, the ten-year nominal Treasury yield fell by 131 basis points to 2.72 percent. In contrast, the yield on the less-liquid ten-year real Treasury bonds rose 41 basis points to 2.28 percent. These circumstances led to a marked narrowing of BEI rates, with the corresponding ten-year BEI rate declining by 172 basis points to 0.44 percent. Of course, not all the declines in the BEI rate were due to shifts in risk and liquidity. Market fundamentals also changed during this period, with increased fears of deflation and a slumping real economy in light of tightening financial conditions. 


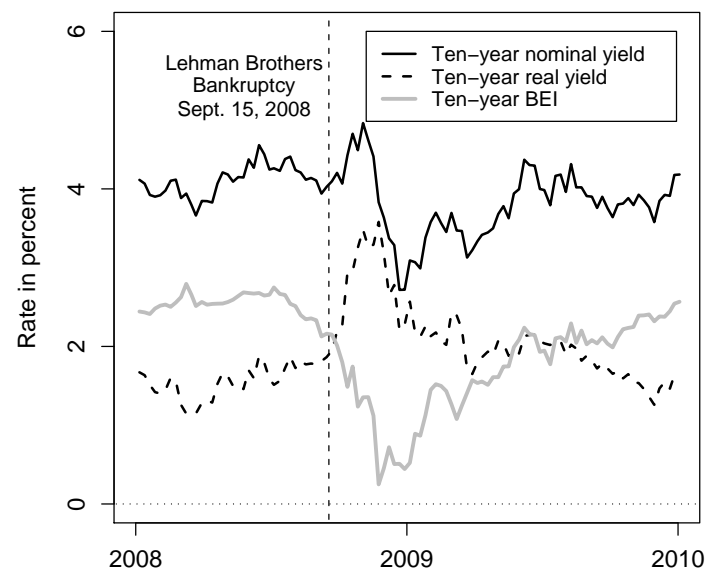

Figure 7: Nominal and Real Ten-Year Zero-Coupon Treasury Yields.

The nominal and real zero-coupon Treasury yields for the ten-year maturity are graphed over the period from January 2008 through December 2009. The observed break-even inflation (BEI) rate is the difference between these yields.

In contrast, the first half of 2009 was characterized by an easing of market tensions. Market participants were mollified by the extraordinary government and central bank policy actions taken around the world to support the functioning of financial markets and stimulate the global economy. In the United States, the Federal Reserve had lowered its target for the federal funds rate to essentially zero and announced, on March 18, that it would purchase up to $\$ 300$ billion of longer-term nominal and real Treasury bonds over the subsequent six months. ${ }^{20}$ During the first six months of June 2009, interest rates retraced much of their earlier movements. The nominal ten-year yield rose by 128 basis points to 4.00 percent, while the real ten-year yield declined by 21 basis points to 2.07 percent. Similarly, during the first half of 2009, the BEI rate rose 149 basis points to 1.93 percent. Finally, the second half of 2009 exhibited lower yield volatility with only a gradual decline in real rates and a slight increase in nominal rates.

The performance of our joint AFNS model of nominal and real Treasury yields depends critically on the quality of the underlying yields data, which appear to have been seriously affected by the Lehman bankruptcy. As one indication of the degree of price distortion during

\footnotetext{
${ }^{20}$ Note that our model does not explicitly account for the effect that central bank purchases might have on Treasury yields. Presumably, indicator variables could be introduced into the model to assess the impact of this change in central bank behavior (as in Christensen, Lopez, and Rudebusch 2009). However, gauging the nature of these estimates could be unreliable given the recent introduction and ongoing nature of the purchases.
} 
this period, Figure 8 presents the difference between off-the-run and on-the-run nominal Treasury yields of a similar maturity. ${ }^{21}$ Historically, this spread is quite small, as the offthe-run security yields about 5 basis points more than the on-the-run security to balance its greater illiquidity. However, from September 2008 through February 2009, this yield spread jumped extremely high. Such an elevated premium on liquidity will likely also alter the spread between nominal Treasury securities and TIPS and effect our model's inference during this period.

While the off-the-run to on-the-run yield spread suggests that the Treasury market dislocations were concentrated in the first few months after the Lehman failure, other measures suggest that liquidity in the Treasury market may have been impaired for a longer period of time. Figure 9 shows the trading volume in nominal and real Treasury bonds from January 2003 through December 2009, which Fleming and Krishnan (2009) argue provides a useful measure of market liquidity. While the levels of the smoothed weekly trading volumes are quite different across the two markets, they both exhibit a similar sustained decline after the Lehman bankruptcy. The average trading volumes for nominal Treasury securities and TIPS each dropped about 16 percent after September 2008. This significant decline in trading activity and the concurrent decline in price discovery could have a negative effect on data quality and model performance.

In addition to liquidity concerns related to the financial crisis, financial markets also had to digest a flood of new U.S. Treasury debt, as the economic recession trimmed federal tax revenues and induced higher fiscal spending. Figure 10 presents the annual gross issuance of nominal and real Treasury debt from 1995 though 2009. From 2003 through 2008, our original estimation sample, the Treasury market experienced a relatively stable period in nominal and real issuance. This stability provides some support for our model's fit and interpretation during this period. In contrast, issuance jumped to $\$ 2.14$ trillion in 2009 . This increased issuance was almost exclusively in nominal debt, which raises concerns about shifts in relative market liquidity. Specifically, the divergence in the supply of nominal Treasuries and TIPS, may boost market segmentation, degrade arbitrage, and lift BEI rates.

\footnotetext{
${ }^{21}$ An on-the-run Treasury security is the most recently issued one of a given maturity, while all previously issued Treasury securities of that maturity are off the run. This spread is calculated by subtracting the sevenyear par-coupon yield on off-the-run Treasury bonds, calculated as in Gürkaynak et al. (2007), from the seven-year par-coupon yield on on-the-run Treasury bonds from the H.15 release by the Treasury Department.
} 


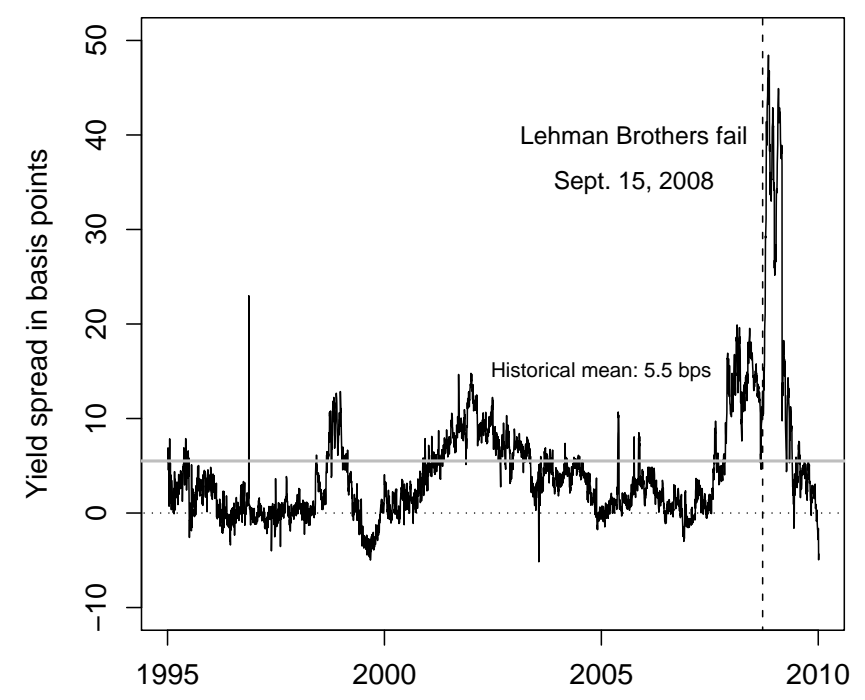

Figure 8: Off-The-Run Minus On-The-Run Treasury Yield.

The seven-year par-coupon off-the-run Treasury yield minus the seven-year par-coupon onthe-run Treasury yield.

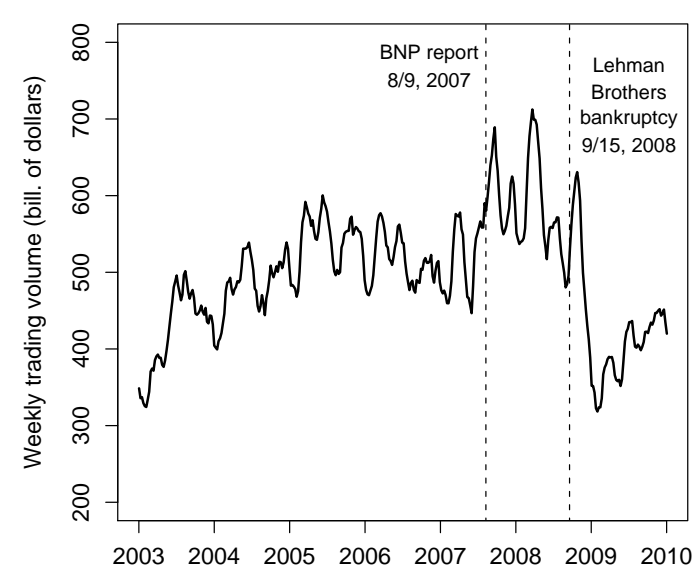

(a) Nominal Treasury bonds.

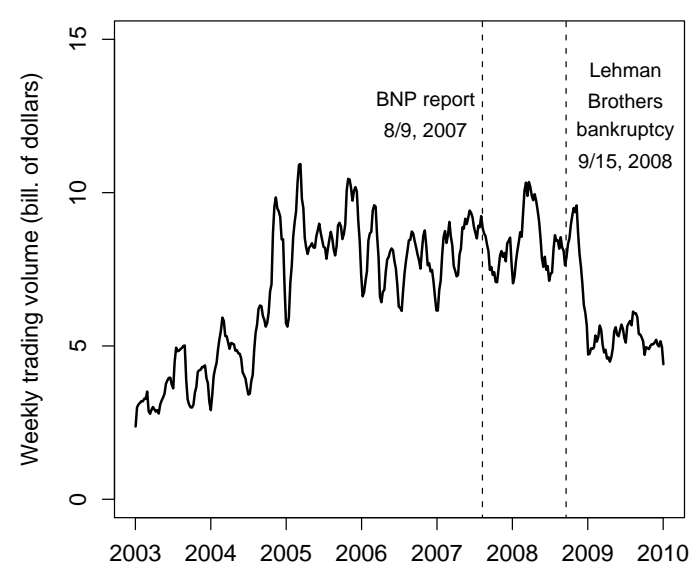

(b) TIPS.

Figure 9: Trading Volume in the Treasury Bond Market.

Weekly trading volume in the secondary market for nominal Treasury bonds and TIPS. The 8-week moving average is calculated using data from the Federal Reserve Bank of New York from November 13, 2002 to December 30, 2009. 


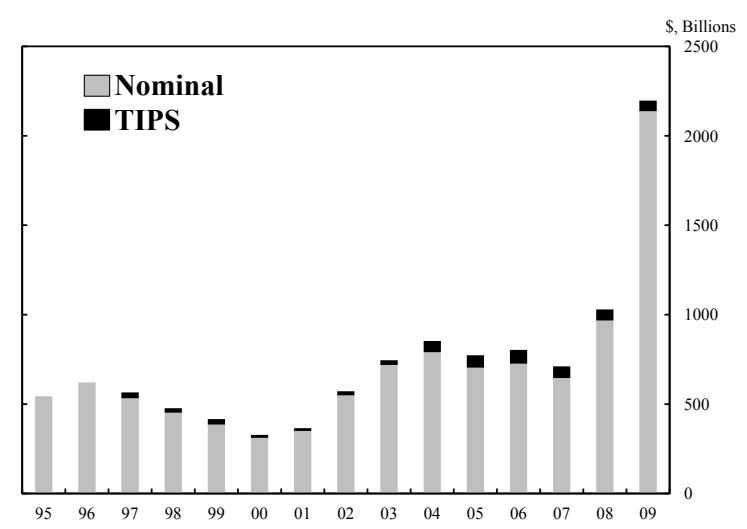

Figure 10: Gross Issuance of U.S. Treasury Notes and Bonds.

Gross issuance of U.S. Treasury notes and bonds is plotted above for both nominal and real debt. Source: U.S. Treasury.

\subsection{Real-time estimation of the joint AFNS model}

The bond market dislocations of the post-Lehman period were substantial, and raise questions about the application of our joint AFNS model and, indeed, any arbitrage-free term structure model to this period. It would not be surprising if our model had trouble fitting the recent financial and economic turmoil - which may be likened to a hundred-year flood in terms of market dislocation, trading liquidity, bond issuance, and central bank policy. One option would be to try to capture these various influences in a complex model that captures institutional and market segmentation effects. Such a model is beyond the scope of our analysis and is likely difficult given the unprecedented nature of the recent events. Instead, we fit our existing plain-vanilla AFNS model to the recent episode. At the very least, such an analysis can provide a canonical "yields-only" baseline that may help provide insight into the magnitude of the potential liquidity and microstructure distortions that have characterized the market since the Lehman bankruptcy.

Our methodological approach is as follows. We use our preferred specification of the model, as detailed in Table 8, for a real-time analysis of the data from January 2008 through December 2009. That is, starting with the first week of January 2008, each new weekly observation is included in the sample, and the model is re-estimated. The model's inflation expectations for the five- and ten-year horizons are presented in Figure 11. The Lehman bankruptcy and subsequent events drove market-based inflation expectations down sharply. Indeed, the fiveyear inflation expectation turned negative in November, suggesting a deflationary outlook. However, these low values were short-lived as the inflation expectations measures rose by year-end. The average inflation expectations during the first half of 2008 were 2.18 and 2.27 


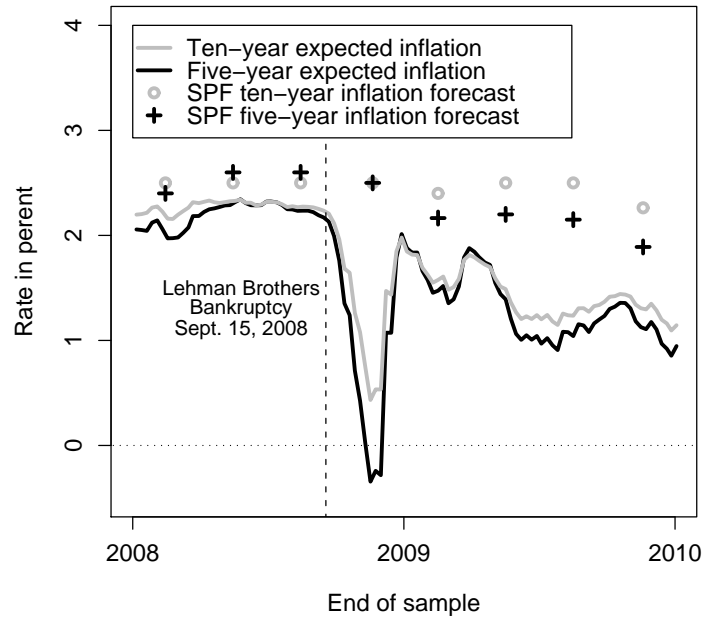

Figure 11: Expected Inflation for 2008 and 2009.

The five- and ten-year average expected inflation rates implied by the rolling estimation of the joint AFNS model are plotted. The survey-based inflation forecasts are from the Survey of Professional Forecasters.

percent at the five- and ten-year horizon, respectively. The corresponding averages for the first half of 2009 were 1.50 and 1.57 percent, and for the second half of 2009, these values were 1.11 percent and 1.29 percent, respectively. Therefore, our joint AFNS model suggests that the deflationary scare observed in BEI rates in late 2008 was short-lived, although longerterm inflation expectations at year-end 2009 had declined by roughly 100 basis points since mid-2008.

Our model also suggests that the inflation risk premium dipped sharply after September 2008, as shown in Figure 12. A plausible interpretation of this result is that the model is translating the relatively low liquidity premium on nominal bonds around year-end 2008 into a very low IRP. However, by mid-2009, as liquidity conditions in the Treasury bond markets stabilized, the IRP measures returned to within their historical ranges. By year-end 2009, the ten-year IRP was at 1.44 percent, near the top of its historical range over the full sample period.

To gauge model fit over the crisis period, we examine the size of the fitted errors for real yields at various maturities as derived from estimating the model over the full sample period through December 2009. The fitted errors are presented in Figure 13. From January 2008 through June 2008, the standard deviations of the fitted errors for the five- and ten-year real yields were 5 and 3 basis points, respectively. (Recall from Table 3 that the corresponding 


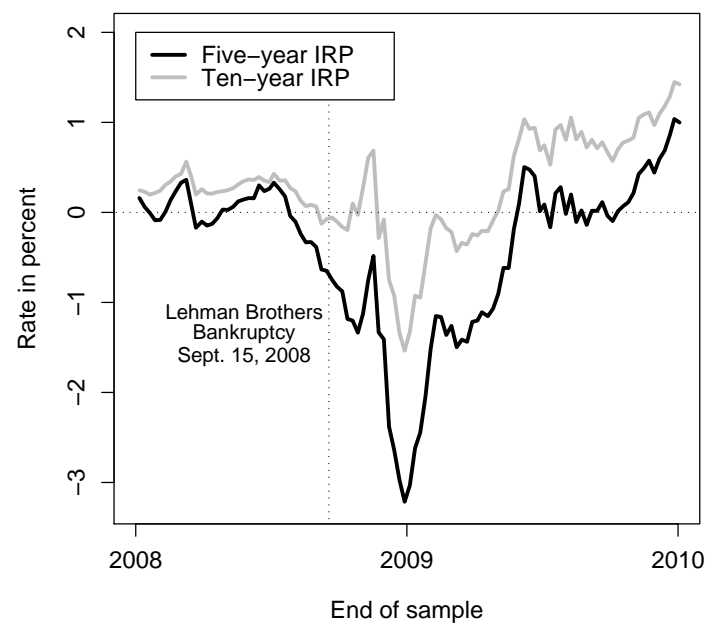

Figure 12: Model-Implied Inflation Risk Premia for 2008 and 2009.

The five- and ten-year inflation risk premiums (IRP) that are implied from the rolling estimation of the joint AFNS model are plotted.

values over the original estimation period ending in March 2008 were 10 and 6 basis points, respectively.) However, the standard deviations from July through December 2008 jumped to 44 and 21 basis points, respectively. They declined to 20 and 8 basis points over the first half of 2009 and even further to 11 and 5 basis points, respectively, over the second half of 2009. The sharp increase in these fitted errors during the second half of 2008 indicates, not surprisingly, that the model had a hard time fitting this extraordinary period. In a sense, the model "looked through" much of the turmoil in Treasury markets by imposing the historical relationships on the data and designating much of the observed fluctuations as error terms. Since the model cannot account separately for the shifts in market liquidity and risk premia during this period, model inference over the period from September 2008 through June 2009 should be viewed with caution. ${ }^{22}$ However, the model's fitted errors for the second half of 2009 appear to be more in line with historical performance, suggesting that market liquidity conditions have improved for this period.

Evidence for the appropriateness of the joint AFNS model's recent performance, at least for the second half of 2009, arises from two sources. First, survey-based measures of long-term inflation expectations reported in 2009, as shown in Figure ??, did not respond as much as

\footnotetext{
${ }^{22}$ In a richer model of the post-Lehman episode that can assess "safe haven" and "convenience" yield motives for holding Treasuries, interest rate swap rates might be useful as an alternative benchmark for the riskless rate that is free from idiosyncratic Treasury movements. That analysis is beyond the scope of our work here.
} 


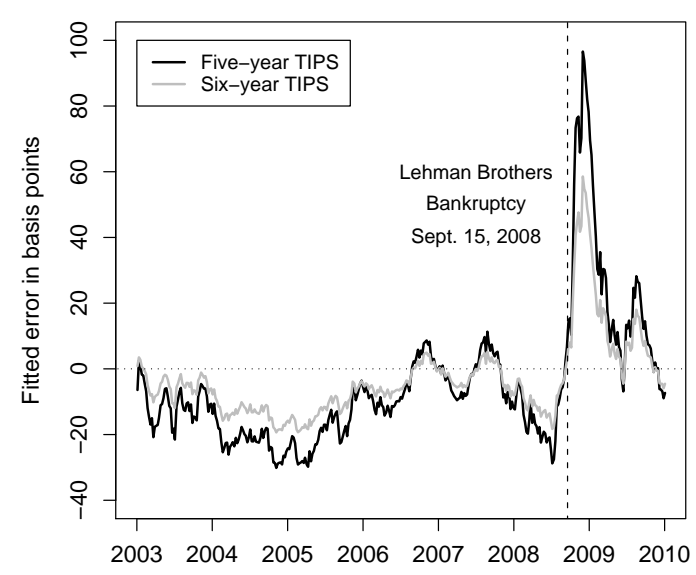

(a) Fitted errors of five- and six-year TIPS.

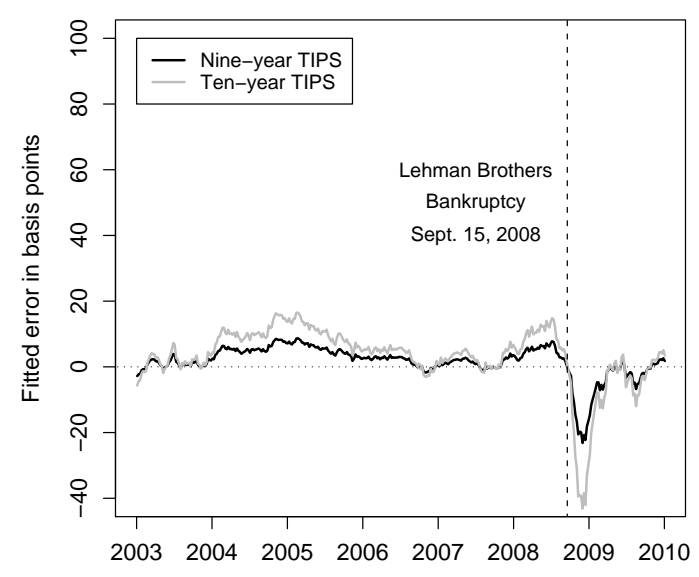

(b) Fitted errors of nine- and ten-year TIPS.

Figure 13: Fitted Errors of TIPS Yields.

The fitted error of the five-, six, nine-, and ten-year TIPS yield series are shown. The joint AFNS model is estimated using the sample ending on December 31, 2009.

market-based measures. The median ten-year forecast from the Survey of Professional Forecasters remained relatively steady through the crisis period at 2.5 percent before exhibiting a slight downturn to 2.25 percent in late 2009. The median five-year forecast from the Survey of Professional Forecasters exhibited a greater decline from 2.6 percent in September 2008 to 2.2 percent in March 2009 and 1.9 by December 2009. The timing of these declines are roughly in line with the pattern in model-implied inflation expectations for 2009. Second, as shown in Figure 14, the model's five- and ten-year inflation expectations are in line with the BEI rates implied by zero-coupon inflation swaps, as reported by Bloomberg. These derivatives contracts have one of the counterparties pay the other the cumulative CPI inflation over the term of the contract at maturity in exchange for a predetermined fixed rate known as the synthetic BEI rate. Based on this rate, the net payment of the contract at maturity would be equal to zero if inflation was equal to this rate over the life of the contract. The correspondence of these series, especially before September 2008, is quite reasonable with correlations of about 0.6 to $0.7 .^{23}$ While both series suggest a deflationary scare in late 2008 and into early 2009, their dynamics both appear to have stabilized, even if at slightly different levels, in the second half of 2009. In short, the liquidity and data quality concerns that arose in the bond markets in September 2008 and persisted into 2009 appear to have diminished to some

\footnotetext{
${ }^{23}$ Haubrich, Pennacchi and Ritchken (2008) use inflation swaps data to model both nominal and real Treasury curves, although Wright (2009) cautions that the inflation swaps market in the U.S. is very small relative to the TIPS market.
} 


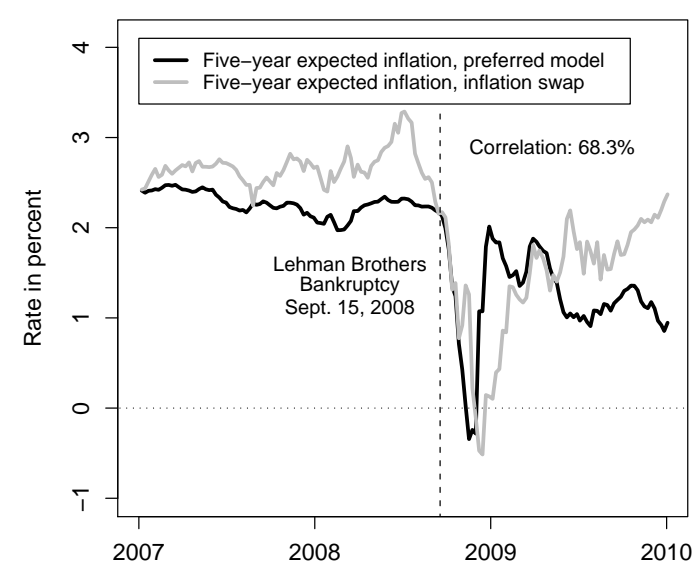

(a) 5-year horizon.

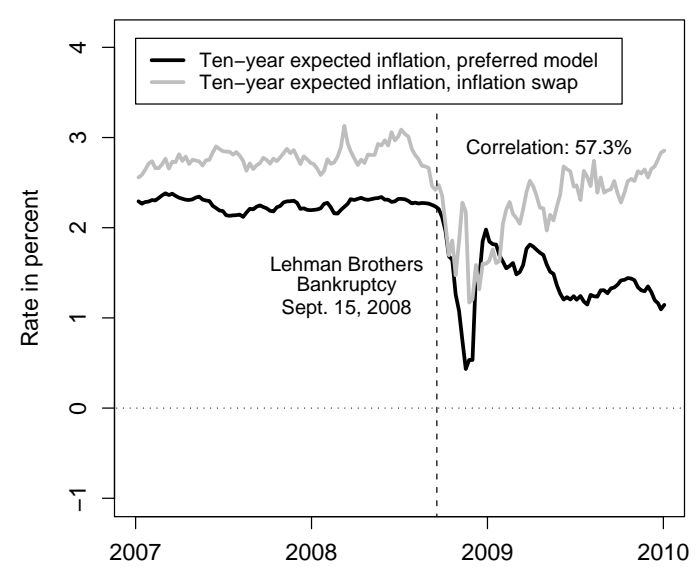

(b) 10-year horizon.

Figure 14: Expected Inflation from the Model and Inflation Swaps.

The five- and ten-year average expected inflation rates implied by the rolling estimation of the joint AFNS model are plotted. The inflation swap data are from Bloomberg.

extent in the latter half of 2009. We view our model inference during the crisis period and into the first half of 2009 as suggestive of the potential magnitude of the Treasury market dislocations. We would argue that inference related to the second half of 2009 should be more useful, but liquidity and market microstructure concerns remain.

\section{Conclusion}

This paper estimates an arbitrage-free model with four latent factors that can capture the dynamics of both the nominal and real Treasury yield curves well and can decompose BEI rates into inflation expectations and inflation risk premiums. The model-implied measures of inflation expectations are correlated closely with survey measures, while the estimated inflation risk premiums fluctuate in fairly close range around zero. The empirical results suggest that long-term inflation expectations have been well-anchored in the period from year-end 2002 through the first quarter of 2008.

Our proposed model has a distinct advantage in that it can be easily estimated because it adopts the dynamic arbitrage-free Nelson-Siegel structure developed by CDR. ${ }^{24}$ Such easy and robust estimation, implemented with the Kalman filter, enables quick updating of the model

\footnotetext{
${ }^{24}$ Christensen, Lopez, and Rudebusch (2009) provide another application of the AFNS structure that also demonstrates its favorable estimation properties.
} 
to incorporate new observations and facilitates the monitoring and forecasting of Treasury yield curves on a real-time basis. The resulting high-frequency measures should be quite desirable to policymakers, central bank staff, and financial market practitioners. 


\section{Appendix}

\section{A). Model estimation procedures}

We estimate all models using the Kalman filter; see Harvey (1989) for further details. The measurement equation for the bond yields is given by

$$
y_{t}=A+B X_{t}+\varepsilon_{t}
$$

where $\varepsilon_{t}$ represents measurement errors that are assumed to be independently and identically distributed (i.i.d.) for each maturity included in the data sample.

For continuous-time Gaussian models, the conditional mean vector and covariance matrix are given by

$$
\begin{aligned}
E^{P}\left[X_{T} \mid \mathcal{F}_{t}\right] & =\left(I-\exp \left(-K^{P} \Delta t\right)\right) \mu^{P}+\exp \left(-K^{P} \Delta t\right) X_{t} \\
V^{P}\left[X_{T} \mid \mathcal{F}_{t}\right] & =\int_{0}^{\Delta t} e^{-K^{P} s} \Sigma \Sigma^{\prime-\left(K^{P}\right)^{\prime} s} d s
\end{aligned}
$$

where $\Delta t=T-t$ and $\exp \left(-K^{P} \Delta t\right)$ is a matrix exponential.

Stationarity of the system under the $P$-measure is ensured if the real component of all the eigenvalues of $K^{P}$ is positive, and this condition is imposed in all estimations. For this reason, we can start the Kalman filter at the unconditional mean and covariance matrix, ${ }^{25}$ denoted as

$$
\widehat{X}_{0}=\mu^{P} \quad \text { and } \quad \widehat{\Sigma}_{0}=\int_{0}^{\infty} e^{-K^{P} s} \Sigma \Sigma^{\prime-\left(K^{P}\right)^{\prime} s} d s .
$$

The state equation in the Kalman filter is given by

$$
X_{t_{i}}=\Phi_{\Delta t_{i}}^{0}+\Phi_{\Delta t_{i}}^{1} X_{t_{i-1}}+\eta_{t_{i}}
$$

where

$$
\begin{array}{r}
\Phi_{\Delta t_{i}}^{0}=\left(I-\exp \left(-K^{P} \Delta t_{i}\right)\right) \mu^{P} \\
\Phi_{\Delta t_{i}}^{1}=\exp \left(-K^{P} \Delta t_{i}\right) \\
\text { and } \eta_{t_{i}} \sim N\left(0, \int_{0}^{\Delta t_{i}} e^{-K^{P} s} \Sigma \Sigma^{\prime-\left(K^{P}\right)^{\prime} s} d s\right)
\end{array}
$$

with $\Delta t_{i}=t_{i}-t_{i-1}$.

\footnotetext{
${ }^{25}$ In the estimation, $\int_{0}^{\infty} e^{-K^{P} s} \Sigma \Sigma^{\prime-\left(K^{P}\right)^{\prime} s} d s$ is approximated by $\int_{0}^{10} e^{-K^{P} s} \Sigma \Sigma^{\prime-\left(K^{P}\right)^{\prime} s} d s$.
} 
In the Kalman filter estimations, all measurement errors are assumed to be i.i.d. white noise. Thus, the error structure is in general given by

$$
\left(\begin{array}{l}
\eta_{t} \\
\varepsilon_{t}
\end{array}\right) \sim N\left[\left(\begin{array}{l}
0 \\
0
\end{array}\right),\left(\begin{array}{ll}
Q & 0 \\
0 & H
\end{array}\right)\right] .
$$

In the estimation, each maturity of the Treasury bond yields has its own measurement error standard deviation, $\sigma^{2}\left(\tau_{i}\right)$.

The linear least-squares optimality of the Kalman filter requires that the white noise transition and measurement errors be orthogonal to the initial state; i.e.,

$$
E\left[f_{0} \eta_{t}^{\prime}\right]=0, \quad E\left[f_{0} \varepsilon_{t}^{\prime}\right]=0 .
$$

Finally, the standard deviations of the estimated parameters are calculated as

$$
\Sigma(\widehat{\psi})=\frac{1}{T}\left[\frac{1}{T} \sum_{t=1}^{T} \frac{\partial \log l_{t}(\widehat{\psi})}{\partial \psi} \frac{\partial \log l_{t}(\widehat{\psi})^{\prime}}{\partial \psi}\right]^{-1}
$$

where $\widehat{\psi}$ denotes the optimal parameter set.

\section{$B)$. A three-factor joint model for nominal and real yields}

Before settling on our joint four-factor model, we considered an alternative three-factor model of nominal and real Treasury yields. The instantaneous nominal risk-free rate was given by

$$
r_{t}^{N}=L_{t}^{N}+S_{t}^{N}
$$

and the usual AFNS dynamics of the three state variables under the pricing measure were imposed. Given that only two factors were needed to model the variation in the real TIPS yields and that both of these factors were correlated with the corresponding nominal yield risk factors, a reasonable specification of the instantaneous real yield process was

$$
r_{t}^{R}=\alpha_{L}^{R} L_{t}^{N}+\alpha_{S}^{R} S_{t}^{N}
$$

Thus, this instantaneous real yield was driven by the same two factors that drive the nominal short rate process.

Both the Akaike Information Criterion and the Bayes Information Criterion lead to the same preferred specification, which is the independent-factors specification of that model that 


\begin{tabular}{|c||c|c|c|c|}
\hline \multicolumn{1}{|c||}{$\begin{array}{c}\text { Maturity } \\
\text { in months }\end{array}$} & \multicolumn{2}{c|}{$\begin{array}{c}\text { Joint four-factor } \\
\text { AFNS mdoel }\end{array}$} & \multicolumn{2}{c|}{$\begin{array}{c}\text { Common three-factor model } \\
\text { Independent factors }\end{array}$} \\
\hline Nom. yields & Mean & RMSE & Mean & RMSE \\
\hline 3 & -0.25 & 10.31 & -4.73 & 43.51 \\
6 & 0.00 & 0.00 & -4.72 & 30.28 \\
12 & 1.74 & 6.16 & -2.56 & 14.89 \\
24 & 2.28 & 4.16 & 0.51 & 2.32 \\
36 & 0.00 & 0.00 & 0.73 & 3.08 \\
60 & -2.89 & 3.87 & -0.55 & 2.42 \\
84 & -0.12 & 2.94 & -0.30 & 1.00 \\
120 & 9.95 & 11.46 & 2.73 & 5.22 \\
\hline TIPS yields & Mean & RMSE & Mean & RMSE \\
\hline 60 & -4.03 & 10.15 & -22.95 & 25.59 \\
72 & -2.25 & 6.54 & -12.97 & 14.86 \\
84 & -0.98 & 3.17 & -5.52 & 6.53 \\
96 & 0.00 & 0.00 & 0.00 & 0.00 \\
108 & 0.77 & 2.91 & 4.04 & 5.14 \\
120 & 1.37 & 5.50 & 6.92 & 9.16 \\
\hline
\end{tabular}

Table 10: Measures of Model Fit for the Three- and Four-Factor Joint AFNS Models.

The mean and root mean squared error of the fitted errors for the three- and four-factor joint AFNS models. All numbers are measured in basis points. The nominal yields cover the period from January 6, 1995, to March 28, 2008, while the real TIPS yields cover the period from January 3, 2003, to March 28, 2008.

only has parameter estimates on the diagonal of the $K^{P}$ matrix. Unfortunately, the estimated three-factor model performs poorly relative to the preferred joint, four-factor model. Table 10 reports the fitted errors for the eight nominal yield maturities and the six real yield maturities.

This table shows that the fit of the three-factor, joint AFNS model is significantly worse for the three-month, six-month, and one-year nominal yields, and for the five-year, six-year, and seven-year real TIPS yields. In addition, the inflation expectations implied by the preferred three-factor model are lower, on average, than those from the preferred, four-factor model. Therefore, we chose to use the joint four-factor model described in the text. ${ }^{26}$

\section{$C)$. Calculation of expected inflation and IRP}

From the theoretical discussion in Section 5.1, it follows that the model-implied expected inflation is given by

$$
\pi_{t}^{e}(\tau)=-\frac{1}{\tau} \ln E_{t}^{P}\left[e^{-\int_{t}^{t+\tau}\left(r_{s}^{N}-r_{s}^{R}\right) d s}\right]
$$

\footnotetext{
${ }^{26}$ Note that the choice of this four-factor relative to a five-factor model that permits for independent fluctuations in the real slope factor prevents us from adequately modeling instances in which the real yield curve becomes inverted. This event is not present in our U.S. dataset, but it has been observed in U.K. data.
} 
For the affine Gaussian framework, we are working within, it holds that

$$
E_{t}^{P}\left[e^{-\int_{t}^{t+\tau}\left(r_{s}^{N}-r_{s}^{R}\right) d s}\right]=\exp \left(B^{\pi}(\tau)^{\prime} X_{t}+A^{\pi}(\tau)\right)
$$

where $B^{\pi}(\tau)$ and $A^{\pi}(\tau)$ are solutions to a system of ODEs given by

$$
\begin{aligned}
& \frac{d B^{\pi}(\tau)}{d \tau}=-\rho_{1}-\left(K^{P}\right)^{\prime} B^{\pi}(\tau), \quad B^{\pi}(0)=0 \\
& \frac{d A^{\pi}(\tau)}{d \tau}=-\rho_{0}+B^{\pi}(\tau)^{\prime} K^{P} \theta^{P}+\frac{1}{2} \sum_{j=1}^{3}\left(\Sigma^{\prime} B^{\pi}(\tau) B^{\pi}(\tau)^{\prime} \Sigma\right)_{j, j}, \quad A^{\pi}(0)=0
\end{aligned}
$$

Here, $K^{P}, \theta^{P}$, and $\Sigma$ reflect the $P$-dynamics of the state variables, while $\rho_{0}$ and $\rho_{1}$ are given by

$$
\rho_{0}=0 \quad \text { and } \quad \rho_{1}=\left(\begin{array}{c}
1 \\
1-\alpha^{R} \\
0 \\
-1
\end{array}\right)
$$

to match the instantaneous rate of change in the price level, $r_{t}^{N}-r_{t}^{R}$. Now, the ODEs above are solved with a standard fourth order Runge-Kutta method.

By Equation 31, we can easily calculate the inflation risk premiums, once we have the corresponding expected inflation, $\pi_{t}^{e}(\tau)$, and fitted nominal and real yields. 


\section{References}

Adrian, Tobias and Hao Wu, 2008, "The Term Structure of Inflation Expectations," Federal Reserve Bank of New York Staff Reports \#362.

Ang, Andrew, Geert Bekaert, and Min Wei, 2008, "The Term Structure of Real Rates and Expected Inflation," Journal of Finance, 63, 797-849.

Bank for International Settlements, 2005, "Zero-Coupon Yield Curves: Technical Documentation," Bank for International Settlement papers, No. 25.

Bernanke, Ben S., 2008, "Remarks on Class Day," Cambridge, Massachusetts June 4.

Campbell, J.Y., Shiller, R.J. and Viceira, L.M., 2009. "Understanding Inflation-Indexed Bond Markets, " Brookings Papers on Economic Activity, Spring, 79-120.

Chen, Ren-Raw, Bo Liu, and Xiaolin Cheng, 2005, "Inflation, Fisher Equation, and The Term Structure of Inflation Risk Premia: Theory and Evidence from TIPS," working paper.

Chernov, Mikhail and Phillipe Mueller, 2008, "The Term Structure of Inflation Expectations," Manuscript, London Business School.

Christensen, Jens H. E., Francis X. Diebold, and Glenn D. Rudebusch, 2007, "The Affine Arbitrage-Free Class of Nelson-Siegel Term Structure Models," Federal Reserve Bank of San Francisco Working Paper 2007-20.

Christensen, Jens H. E., Francis X. Diebold, and Glenn D. Rudebusch, 2008, "An ArbitrageFree Generalized Nelson-Siegel Term Structure Model," The Econometrics Journal, 12, C33-64.

Christensen, Jens H. E., and Jose A. Lopez, 2008, "Common Risk Factors in the U.S. Treasury and Corporate Bond Markets: An Arbitrage-Free Dynamic Nelson-Siegel Modeling Approach," " Manuscript, Federal Reserve Bank of San Francisco.

Christensen, Jens H. E., Jose A. Lopez, Glenn D. Rudebusch, 2008, "Do Central Bank Liquidity Facilities Affect Interbank Lending Rates?," Federal Reserve Bank of San Francisco Working Paper \#2009-13.

Chun, A.L., 2009. "Expectations, Bond Yields and Monetary Policy," Manuscript, Department of Finance, Copenhagen Business School. 
Cochrane, John, 2001, Asset Pricing, Princeton: Princeton University Press.

Dai, Qiang, and Kenneth J. Singleton, 2002, "Expectations Puzzles, Time-Varying Risk Premia, and Affine Models of the Term Structure," Journal of Financial Economics, Vol. 63, 415-441.

D'Amico, Stefania, Don H. Kim, and Min Wei, 2008, "Tips from TIPS: the informational content of Treasury Inflation-Protected Security prices," Finance and Economics Discussion Series No. 30, Federal Reserve Board.

Diebold, F.X., and C. Li, 2006, "Forecasting the Term Structure of Government Bond Yields," Journal of Econometrics, Vol. 130, 337-364.

Duffee, Gregory R., 1996, "Idiosyncratic Variation of Treasury Bill Yields," Journal of Finance, Vol. 51, 527-552.

Duffee, Gregory R., 2002, "Term Premia and Interest Rate Forecasts in Affine Models," Journal of Finance, Vol. 57, 405-443.

Duffee, Gregory R., 2008, "Forecasting with the Term Structure: The Role of No-Arbitrage," manuscript, Johns Hopkins University.

Duffie, Darrell, and Rui Kan, 1996, "A Yield-Factor Model of Interest Rates," Mathematical Finance, Vol. 6, 379-406.

Fleming, M. and Krishnan, N., 2009. "The Microstructure of the TIPS Market," Federal Reserve Bank of New York Staff Reports, No. 414.

Grishchenko, Olesya V., and J, Huang, 2009. "Inflation Risk Premium: Evidence from the TIPS Market," Manuscript, Smeal College of Business, Pennsylvania State University.

Gürkaynak, Refet S., Brian Sack, and Jonathan H. Wright, 2007, "The U.S. Treasury Yield Curve: 1961 to the Present," Journal of Monetary Economics, Vol. 54, 2291-2304.

Gürkaynak, Refet S., Brian Sack, and Jonathan H. Wright, 2008, "The TIPS Yield Curve and Inflation Compensation," American Economics Journal: Macroeconomics, forthcoming.

Harvey, A.C., 1989, Forecasting, structural time series models and the Kalman filter, Cambridge: Cambridge University Press. 
Haubrich, Joseph, George Pennacchi, and Peter Ritchken, 2008, "Estimating Real and Nominal Term Structures using Treasury Yields, Inflation, Inflation Forecasts and Inflation Swap Rates," Federal Reserve Bank of Cleveland Working Paper \#2008-10.

Hördahl, Peter, and Oreste Tristani, 2007, "Inflation Risk Premia in the Term Structure of Interest Rates," Bank for International Settlements Working Paper \#228.

Hördahl, Peter, and Oreste Tristani, 2008, "Inflation Risk Premia in the U.S. and the Euro Area," manuscript, Bank for International Settlements.

Joyce, Michael, Peter Lildholdt and Steffen Sorensen, 2009, "Extracting Inflation Expectations and Inflation Risk Premia from the Term Structure: A Joint Model of the U.K. Nominal and Real Yield Curves," Bank of England Working Paper \#360.

Kim, Don H., and Athanasios Orphanides, 2005, "Term Structure Estimation with Survey Data on Interest Rate Forecasts," Finance and Economics Discussion Series, No. 48, Federal Reserve Board.

Litterman, R., and J. A. Scheinkman, 1991, "Common Factors Affecting Bond Returns," Journal of Fixed Income, Vol. 1, 62-74.

Nelson, Charles R., and Andrew F. Siegel, 1987, "Parsimonious Modeling of Yield Curves," Journal of Business, Vol. 60, 473-489.

Roush, J.E., 2008, "The 'Growing Pains' of TIPS Issuance," Finance and Economics Discussion Series No. 8, Federal Reserve Board.

Sack, Brian, and Robert Elsasser, 2004, "Treasury Inflation-Indexed Debt: A Review of the U.S. Experience," Economic Policy Review, Federal Reserve Bank of New York, Vol. 10, May, 47-63.

Svensson, Lars E. O., 1994. Estimating and Interpreting Forward Rates: Sweden 1992-4, National Bureau of Economic Research Working Paper \#4871.

Wright, J.H., 2009. "Comment on Understanding Inflation-Indexed Bond Markets, " Brookings Papers on Economic Activity, Spring, 126-138. 